Marc Tarrés Vives

Profesor Dr. Asociado de Derecho Administrativo Universitat de Girona

\title{
Las normas técnicas en el Derecho Administrativo
}

SUMARIO: I. INTRODUCCIÓN. ASPECTOS QUE JUSTIFICAN EL INTERÉS POR LAS NORMAS TÉCNICAS. II. LA NORMA TÉCNICA EN EL DERECHO ADMINISTRATIVO ESPAÑOL. 1. ACTO ADMINISTRATIVO Y NORMA TÉCNICA. 2. REGLAMENTO Y NORMA TÉCNICA. LA REGULACIÓN DE LA TÉCNICA POR EL ORDENAMIENTO JURÍDICO: PRINCIPIO DE LEGALIDAD Y REGLAMENTO INDEPENDIENTE. 3. LA PROBLEMÁTICA REMISIÓN A LA NORMA TÉCNICA DESDE LA NORMA JURÍDICA. LA REGULACIÓN DE LA TÉCNICA POR EL ORDENAMIENTO DE LA TÉCNICA. A). La remisión directa al ordenamiento de la técnica. a.1) El reenvío estático o recepticio a la norma técnica: el problema de la publicidad normativa. a.2) El reenvío dinámico o remisión a la norma técnica. B) La remisión indirecta al ordenamiento de la técnica: cláusulas generales y norma técnica.

\section{INTRODUCCIÓN. ASPECTOS QUE JUSTIFICAN EL INTERÉS POR LAS NORMAS TÉCNICAS}

El de las normas técnicas es un tema que en los últimos años viene siendo objeto de atención por parte de los juristas y, muy especialmente, de los iuspublicistas. A mi parecer, según iré exponiendo, existen diferentes aspectos que ayudan a explicar ese inusitado interés por una materia en apariencia tan ajena al ámbito jurídico y que, desde luego, interesa principalmente, por motivos bien diferentes, a las disciplinas científico-experimentales.

El aspecto histórico y sociológico

En España, a diferencia de otros Estados europeos, no existe una tradición histórica a la que puedan ser referidas las normas téc-

Documentación Administrativa / nº. 265-266 (enero-agosto 2003) 
nicas ${ }^{1}$. Pese a ello, puede decirse que se trata de un tema integrante de una ya algo más que centenaria relación entre la Técnica y el Derecho. Relación que hoy adquiere un recobrado protagonismo ante unas transformaciones que, como antaño, exigen una decidida acción por parte del poder público. Si ha existido y sigue existiendo una disciplina jurídica claramente vinculada a la Técnica, esa es, sin lugar a duda, el Derecho administrativo ${ }^{2}$. Es precisamente él quien durante el siglo XIX abre el camino al desarrollo del ferrocarril y el tranvía a través de la expropiación forzosa, o mediante la autorización administrativa de las instalaciones industriales garantiza una necesaria estabilidad a las inversiones llevadas a cabo por los empresarios ${ }^{3}$. Bien puede decirse que, en sus inicios, el Derecho administrativo es también el Derecho de la técnica ${ }^{4}$. Por su parte, el Estado contemporáneo se consolida en muy buena medida gracias a la técnica y hace de ella una de sus principales señas. Así, durante el siglo XX la incentivación del desarrollo científico y técnico constituye una constante en la transformación del Estado en Estado social. Es conocida, y no casual, la atención que Ernst FORSTHOFF $^{5}$ prestará al necesario control de la técnica por el Estado para

1 Tradición que en otros países es ya secular. Por ejemplo, en Alemania, la creación de especificaciones técnicas por asociaciones de ingenieros y su reconocimiento desde normas legales es ya una realidad ligada a la caldera de vapor durante el siglo XIX. Tales especificaciones eran tomadas por la Administración como «reglas reconocidas de la ciencia y de la técnica» (annerkannte Regeln der Wissenschaft und Technik). Vid. la interesante obra de G.-S. SONNENBERG, Hundert Jahre Sicherheit. Beiträge zur technischen und administrativen Entwicklung des Dampfkesselwesens in Deutschland 1810 bis 1910, VDI-Verlag, Düsseldorf, 1968. Más ampliamente véase M. TARRÉs VIVES, Normas técnicas y ordenamiento jurídico, Tirant lo Blanch, Valencia, 2003, pp. 110 y ss.

${ }^{2}$ Véase J. Esteve PARDO, «El común origen del Derecho Administrativo y la ingeniería civil, en el XIX», en La configuración jurídico política del Estado liberal en España. Actas del Congreso en conmemoración del segundo centenario del nacimiento de D. Alejandro Oliván (1796-1996), Universidad de Zaragoza, 1996, pp. 121-130.

3 La necesidad de fomentar la inicipiente industrialización comportó un nuevo planteamiento doctrinal de la teoría de las relaciones de vecindad en el ámbito de las inmisiones. El nuevo esquema suponía que las instalaciones industriales debían cumplir con los mínimos de protección fijados por el Estado y, a cambio, podían operar en un marco estable frente a posibles denuncias de los ciudadanos. Vid. J. EGEA, «Relaciones de vecindad, desarrollo industrial y medio ambiente», en Derecho del Medio Ambiente y Administración Local (J. Esteve Pardo, coord.), Madrid, Civitas, 1996, pp. 76-77; A. NOGUEIRA LóPEZ, «Evolución de las técnicas de tutela ambiental en la Unión Europea», Revista Aragonesa de Administración Pública, nº 12, 1998, pp. 63-64. La relación entre libertad de industria y regulación jurídico-pública en la protección contra las inmisiones se trata detalladamente, para el caso alemán, en la obra de G. LIEs-BENACHIB, Inmissionsschutz im 19. Jahrhundert, Duncker-Humblot, Berlin, 2002, pp. 177 y ss.

${ }^{4}$ En este sentido se manifiesta D. MURSwIEK, «Die Bewältigung der wissenschaftlichen und technischen Entwicklungen durch das Verwaltungsrecht» («El dominio del desarrollo científico y técnico a través del Derecho administrativo»), en Veröffentlichungen der Vereinigung der Deutschen Staatsrechtslehrer (VVDStRL), Berlín, 1990, nº 48, p. 209.

5 Vid. E. FORSTHOFF, «Der Jurist in der industriellen Gesellschaft», NJW, 1960, pp. 1273 1277. Ernst Forsthoff se doctoró en el año 1923 con Carl Schmitt, uno de los juristas que más tempranamente percibieron el carácter no neutral de la Técnica en la realización del Estado. 
garantizar esa procura existencial (Daseinvorsorge $)^{6}$ acuñada por él y propia del Estado social de la posguerra ${ }^{7}$. Esa idea junto a los avances técnicos operados en las últimas cinco décadas han posibilitado una población más sana, rica y educada. Un logro construido a partir de una acción planificadora y centralizada que encuentra en la estandarización una auténtica panacea universal. No resulta extraño que, tras el importante papel que habían desempeñado durante la II Guerra Mundial, los estándares o normas técnicas se extendiesen a todo el sistema industrial y se prodigasen tanto en los Estados capitalistas como socialistas. Sin ellas, por ejemplo, habría sido -es- imposible dar satisfacción a una demanda generalizada de productos por parte de una población ávida de prestaciones materiales.

El Estado del bienestar constituye, pues, la respuesta adecuada a un conjunto determinado de circunstancias que -hay que reconocerlo- son hoy diferentes. El propio estilo de vida estandarizado mostraría hoy vías de agua ante el éxito creciente de productos singulares que huyen del estándar. Pero, sin duda, el cambio más trascendental ha operado en nuestra percepción ante la realidad del progreso científico-técnico. Una realidad que nos muestra cómo cada avance coincide con un problema o desventaja comparables. Así, por ejemplo, la tecnología alimentaria ha logrado una sobreproducción de alimentos que si bien evita el peligro de la hambruna -por desgracia no en todo el planeta-, incrementa a la par el riesgo para la salud del ser humano ante nuevos productos o métodos de elaboración ${ }^{8}$. Otro ejemplo es el de la telefonía móvil, de tan rápida expansión como veloces han sido las suspicacias levantadas frente a las antenas que permiten asegurar la cobertura del servicio. La situación de los poderes públicos ante este escenario descrito no resulta en absoluto fácil ${ }^{9}$. Especialmente por una ra-

6 En este tema véase su trabajo «La previsión existencial en la edad de la técnica», publicado en el número 100 (1966) de Documentación Administrativa. El término Daseinvorsorge mantiene su vigencia en la literatura jurídica alemana si bien con un sentido distinto al dado por el Profesor de Heidelberg. Vid. M. RONELLENFITSCH, «Daseinvorsorge als Rechtsbegriff-Aktuelle Entwicklungen im nationalen und europäischen Recht», en Ernst Forsthoff. Kolloquium ans Anlass des 100. Geburtstags von Prof. Dr. Dr. h.c. Ernst Forsthoff, Duncker-Humblot, Berlín, 2003, pp. 53-114. El influjo del Derecho europeo ha llevado a tomar dicha palabra como equivalente a lo que nosotros conocemos como servicios de interés público. Véase J. AXEL KäMMERER, «Daseinvorsorge als Gemeinschaftsziel oder: Europas Sozialen Gewissen», en NVwZ, nº 9, 2002, p. 1041 y ss.

7 Las ideas de Forsthoff encontraron eco en nuestro país gracias a las aportaciones del Profesor Lorenzo MARTÍN-RETORTILLO, fundamentalmente en su trabajo «La configuración jurídica de la Administración pública y el concepto de Daseinvorsorge», RAP, n ${ }^{\circ}$ 38, 1962, p. 35 y ss. También, más tarde, el trabajo del Profesor Manuel GARCíA PELAYO «El Estado social y sus implicaciones», incluido en su conocida obra Las transformaciones del Estado contemporáneo, Alianza, Madrid, 1977, especialmente pp. 26-30.

8 En este tema véase el sugerente trabajo de Mariola RODRÍGUEZ FONT, «El análisis del riesgo en los alimentos transgénicos: una perspectiva jurídica», en Actas del II Congreso Internacional de Tecnoética, Barcelona, 2003, pp. 245-259.

9 En el caso de las antenas de telefonía móvil cabe destacar el buen tino en algunas sentencias que ante situaciones de auténtico vacío legal han resuelto atendiendo a un mínimo de 
zón fundamental, la propia ciencia es hoy incapaz de ofrecer una respuesta unívoca que afirme o niegue la existencia de riesgos inaceptables ${ }^{10}$. En otras palabras, asistimos a una constante autorrefutación pública de la argumentación científica ${ }^{11}$. Esta situación de incerteza ante el riesgo en la que se ve sumida la sociedad encuentra también reflejo en el Derecho. Ello explica, tal como puede verse en otro de los trabajos que conforman este número monográfico ${ }^{12}$, la aparición del llamado principio de cautela o precaución $^{13}$, aplicable a situaciones de incertidumbre científica o técnica. De manera muy simplificada la aplicación de este principio supondría que lo técnicamente disponible puede ser jurídicamente indisponible por resultar política y socialmente inaceptable. No resulta extraño que tratando estas cuestiones no sólo se encuentren aportaciones jurídicas, sino también desde el ámbito de la sociología. Disciplina que también ha abordado con interés la problemática de las normas técnicas ${ }^{14}$.

cautela. En este sentido la Sentencia de la Sala de lo Contencioso-Administrativo del Tribunal Superior de Cataluña, de 19 de octubre de 2001, Berlín, 2003, pp. 53-114 (Ar. $51612 / 2002)$, señala que «ante la duda en materia tan delicada y trascendente como la incidencia para la salud y el medio ambiente debe abogarse, aunque sólo sea por precaución, por el máximo de seguridad y garantías». En este mismo tema debe destacarse la Sentencia del Juzgado de Primera Instancia de Bilbao (n ${ }^{\circ}$ 2), de 9 de junio 2001 (AC 1812/2001). Véase G. DOMÉNECH PASCUAL, «Las ordenanzas municipales reguladoras de las instalaciones de radiocomunicación», REDA, n $\mathrm{n}^{\circ} 117,2003$, pp. 33 y ss.

10 Sobre la incidencia que plantea la incerteza en la tipificación del riesgo permitido, véase J. EsTEVE PARDO, «De la política administrativa a la gestión de riesgos», $R E D A, \mathrm{n}^{\circ} 119,2003$, pp. 337 y ss.

11 Advierte el sociólogo alemán Ulrich BECK como «(C)asi todas las objeciones en contra de los riesgos de una tecnología se formulan en base al pensamiento predominante en la técnica y las ciencias naturales. Y también las terapias y alternativas ofrecidas provienen casi siempre de los arsenales de la técnica». Véase U. BECK, Políticas ecológicas en la edad del riesgo, Ed. El Roure, Barcelona, 1998, p. 207.

12 El que bajo el título «Ciencia y Derecho ante los riesgos para la salud evaluación, decisión y gestión» escribe J. ESTEVE PARDO.

${ }^{13}$ La aplicación de este principio va ligada a la evaluación del riesgo a partir de dos actividades complementarias y que deben diferenciarse: la determinación del nivel de riesgo considerado inaceptable y la evaluación científica de los riesgos. En este sentido resultan ilustrativas las recientes Sentencias del Tribunal de Primera Instancia (Sala Tercera) de las Comunidades Europeas, de once de septiembre de 2002 (asuntos T-13/99 -Pfizer Animal Health SA $v$. Consejo- y T-70/99 -Alpharma Inc. $v$. Consejo-). En ambas se señala que «(L)a determinación del nivel de riesgo considerado inaceptable depende del modo en que la autoridad pública competente valore las circunstancias específicas de cada caso. A este respecto, dicha autoridad puede tener en cuenta, en particular, la gravedad de las repercusiones para la salud humana si dicho riesgo se materializara, incluida la magnitud de los posibles efectos perjudiciales, su reversibilidad o los posibles efectos a largo plazo de los daños causados, así como el mayor o menor grado de concreción con que se perciba el riesgo en función de los conocimientos científicos disponibles» (véanse los apartados 150 a 153 y 163 a 166, respectivamente). Vid. F. J. SANZ LARRUGA, «El principio de precaución en la jurisprudencia comunitaria», en Revista Aranzadi de Derecho Ambiental, nº 1, 2002, pp. 117-131; M. TARRÉs VIVES, «El Derecho ante los riesgos de la modernidad: el principio de precaución», en Actas del II Congreso Internacional de Tecnoética, Barcelona, 2003, pp. 261 y ss.

${ }^{14}$ Véase por ejemplo, H. VoELzKow, Private Regierungen in der Techniksteverung. Eine sozialwissenschaftliche Analyse der technischen Normung, Campos, Fráncfort del Meno, 1196. 
DA-2003, núms. 265-266. MARC TARRÉS VIVES. Las normas técnicas en el Derecho Administrativ...

El aspecto jurídico

Paradójicamente, todas esas incertidumbres no han hecho más que fortalecer el papel de las normas técnicas de origen privado e incrementar su función implementadora en el Derecho. La definición, por ejemplo, de las mejores técnicas disponibles ${ }^{15}$ o la determinación de los niveles de riesgo - p. ej., la fijación de valores límite de emisión- no se realiza por regla en el seno de las instancias políticamente legitimadas, sino en organizaciones y entidades en las que el elemento tecnocrático prima sobre el democrático. Además, el pretendido carácter neutro de la norma técnica debe ser relativizado. Los hechos nos demuestran que la normalización no es sólo una tarea estrictamente técnica, en ella existen también otras ponderaciones, fundamentalmente de carácter económico ${ }^{16}$. Así, la norma técnica puede no adaptarse a un progreso técnico «disponible» sencillamente por no ser asumible económicamente ${ }^{17}$. Más preocupante, si cabe, es el establecimiento en disposiciones reglamentarias de los valores límite de emisión basados en conocimientos científicos. La finalidad de estos valores es lógicamente la de prevenir efectos nocivos para la salud humana. Ello significa entonces que el «valor límite», su «umbral de alerta» o su «margen de tolerancia» son definidos tomando en consideración los niveles medios de salud de la población. Es decir, el propio ser humano es tomado como estándar prescindiéndose de aquellos grupos con mayor predisposición para el riesgo, como pueden ser niños y ancianos ${ }^{18}$. Se trata,

15 Vid. José ESTEVE PARDO, Técnica, riesgo y Derecho (Tratamiento del riesgo tecnológico en el Derecho ambiental), Civitas, Madrid, 1999, p. 92 y ss.

16 Por ejemplo, la fijación de unas determinadas especificaciones técnicas en lugar de otras puede suponer una restricción a la libre competencia. En este tema véase Jean-Baptiste RACINE, «Normalisation, certification et Droit de la concurrence», Rev. int. dr. écon., 1998, p. 147 y ss.; Vicente ÁlvareZ GaRCíA, «La aplicación de las reglas del Derecho de la competencia en el mundo de la técnica», $R A P, \mathrm{n}^{\circ} 152,2000$, p. 153 y ss.; Sonia RODRÍGUEZ-CAMPOS GONZÁLEZ, «Normalización industrial y Derecho comunitario de la competencia», $R A P, \mathrm{n}^{\circ}$ 158, 2002, p. 187 y ss.

17 Así, por ejemplo, la Ley 16/2002, de 1 de julio, de Prevención y control integrados de la contaminación, refiere en su artículo 3, letra ñ), la expresión «mejores técnicas disponibles», entendiendo por «disponibles», «las técnicas desarrolladas a una escala que permita su aplicación en el contexto del correspondiente sector industrial, en condiciones económicas y técnicamente viables, tomando en consideración los costes y los beneficios, tanto si las técnicas se utilizan o producen en España, como si no, siempre que el titular pueda tener acceso a ellas en condiciones razonables»-cursiva nuestra-. En relación con este precepto hay que destacar el contenido del Anexo 4 de la Ley en el que se establecen los «Aspectos que deben tenerse en cuenta con carácter general o en un supuesto particular cuando se determinen las mejores técnicas disponibles definidas en el artículo 3.ñ), teniendo en cuenta los costes y ventajas que pueden derivarse de una acción y los principios de precaución y prevención».

$18 \mathrm{Al}$ respecto, con un minucioso estudio de la legislación alemana y norteamericana, véase la interesante obra de Monika BöHM, Der Normmensch, Mohr, Tubinga, 1996. 
sin duda, de un gran tema que ahora debemos orillar para ceñirnos al papel desarrollado por las normas técnicas con relación a los valores límite. Más que fijar los valores en sí, la normalización desempeña allí una importantísima función en lo que se refiere a los métodos de medición y análisis a los cuales, sin mayores problemas, se remite la legislación vigente ${ }^{19}$.

La incorporación o, mejor dicho, la referencia a la norma técnica privada desde la norma jurídica y la concreción de ésta por aquélla es, sin duda, uno de los aspectos más relevantes que interesan al jurista y principalmente, por ahora y en nuestro país, a los administrativista ${ }^{20}$. En este sentido no es de extrañar que al abordar el estado actual de la técnica legislativa MONTORO CHINER haya destacado cómo a la "Ciencia de la legislación nunca se le ha planteado una cuestión tan apasionante como la del tratamiento de las normas técnicas» ${ }^{21}$. Advierte también esta autora cómo, además, el criterio científico «determina el ámbito de aplicación de una norma o la exclusión de su supuesto de hecho», lo cual supone que «la elección del criterio afecta no sólo al contenido de regulación, sino también al ámbito de aplicación del Derecho, y esa elección tiene trascendencia constitucional» ${ }^{22}$. Con rela-

19 Por su especial relevancia para la salud humana y el medio ambiente cabe destacar el Real Decreto 1073/2002, de 18 de octubre, sobre evaluación y gestión de la calidad del aire ambiente en relación con el dióxido de azufre, dióxido de nitrógeno, óxidos de nitrógeno, partículas, plomo, benceno y monóxido de carbono. En esta disposición se establecen los criterios para la medición de las concentraciones de los distintos contaminantes, así como los objetivos de calidad de los datos y presentación de resultados. De este modo en el Anexo X puede verse que en lo que respecta a los objetivos de calidad de los datos y presentación de los resultados de la evaluación de la calidad del aire, la incertidumbre de la medida vendrá definida en la norma UNE 82009-1:1998. En el mismo sentido, por ejemplo, el Anexo XI establece como método de referencia para el análisis de dióxido de nitrógeno y óxidos de nitrógeno el contenido en la norma UNE 77212:1993 (equivalente a ISO 7996:1985). Todo ello no excluye que las «autoridades competentes» puedan utilizar cualquier otro método si pueden demostrar que da resultados equivalentes al método contenido en la norma.

20 Cabría ahí destacar el trabajo pionero de Elisenda MALARET I GARCíA, «Una aproximación jurídica al sistema español de normalización de productos industriales», $R A P, \mathrm{n}^{\circ} 116,1988$; también el pormenorizado estudio que le dedica Germán FERNÁNDEZ FARRERES en su capítulo de «Industria» dentro de la obra Derecho administrativo económico, t. II (S. MARTíN-RETORTILLO, dir.), La Ley, Madrid, 1991. El papel que desempeñan las normas técnicas en la delimitación del riesgo tecnológico es analizado por José EsTEVE PARDO en su monografía Técnica, riesgo y Derecho (Tratamiento del riesgo tecnológico en el Derecho ambiental), Ariel, Barcelona, 1999. En los últimos cuatro años el número de libros y artículos relacionados con esta materia acrece considerablemente, entre otros podemos citar: Vicente ÁLVAREZ GARCÍA, La normalización industrial, Tirant lo Blanch, Valencia, 1999; el mismo autor ha abordado también este tema en diferentes artículos posteriores, entre ellos: Juan Antonio CARRILlo DONAIRE, El Derecho de la seguridad y de la calidad industrial, Marcial Pons, Madrid, 2000; Manuel IZQUIERDO CARRASCO, La seguridad de los productos industriales (Régimen jurídico-administrativo y protección de los consumidores), Marcial Pons, Madrid, 2000; Ramon J. MOLES I PLAZA, Derecho y calidad (El régimen jurídico de la normalización técnica), Ariel, Barcelona, 2001; Marc TARRÉs VIVES, Normas técnicas y ordenamiento jurídico, Tirant lo Blanch, Valencia, 2003.

21 Vid. Ma . J. MONTORO CHINER, La evaluación de las normas. Racionalidad y eficiencia, Atelier, Barcelona, 2001, p. 48.

22 Ibidem, p. 49. 
ción a esta consideración cabría señalar que -a diferencia de la norma técnica- la determinación del citado criterio es formalmente adoptada por el legislador tras su discusión en el seno de algún comité científico, existente o creado ad hoc, en el que la figura del experto adquiere relevancia. El problema que plantea este tipo de legislación apoyada en el expertus es el de la legitimación política de la decisión. Cabe decir, sin embargo, que el experto no sustituye -o no debería sustituir-a quien legítimamente debe tomar la decisión ${ }^{23}$; su dictamen -información- se emite y, en su caso, adopta en el seno de instituciones políticamente legitimadas para convertir en Derecho el criterio científico ${ }^{24}$.

La referencia al papel del experto en el seno de los comités científi$\cos$ o agencias ${ }^{25}$ resulta también necesaria porque su problemática no puede ser equiparada con la de la normalización; aquéllos forman parte del engranaje institucional del Estado democrático de Derecho, los organismos de normalización no. Éstos son expresión de otra cosa -en nuestra opinión no propiamente corporativismo-, de lo que viene en llamarse autorregulación. Como bien ha señalado ESTEVE PARDO, las normas técnicas «carecen de la legitimación política que les otorgaría el respaldo de la comunidad política, y carecen también de cobertura habilitante en la Constitución. No son elaboradas por instancias políticamente relevantes, ni tan sólo por organizaciones constitucionalmente reconocidas para la satisfacción de intereses generales como son las Administraciones públicas ${ }^{26}$. Considerando las normas técnicas como una de las muestras más genuinas de autorregulación, el problema de la legitimidad es cla-

${ }^{23}$ Como bien advierte Hans-Georg GADAMER, el experto «está clasificado por debajo de quienes adoptan las decisiones en la vida político-social», vid. «Los límites del experto», en La herencia de Europa. Ensayos, Península, Barcelona, 2000, p. 127 y ss.

${ }^{24}$ En el Derecho la creación normativa formal y el grado de vinculación de cada norma va ligada a la necesaria concurrencia de dos presupuestos: legitimidad y legalidad. El Derecho es el ordenamiento competente del que deriva la legalidad que, a su vez, encuentra su legitimidad en quienes ostentan el poder dentro del sistema político. Se trata, según el sociólogo Helmut WILLKE, de un proceso recurrente de autolegitimación: la política legitima el Derecho; el Derecho legitima la acción política y social; la sociedad legitima la política, etc. Así, la política, en un sentido estricto, constituye el sistema que permite la elaboración de decisiones obligatorias (poder legislativo) de las cuales el responsable último es el Estado. La Administración es el sistema para la implementación de aquellas decisiones políticas (poder ejecutivo). Y, finalmente, el sistema jurídico es aquél encargado de regular los conflictos derivados de la aplicación de aquellas decisiones (poder judicial). Vid. H. WiLLKe, Ironie des Staates. Grundlinien einer Theorie des Staates polyzentrischer Gesellschaft, Suhrkamp, Fráncfort del Meno, 1992, p. 215.

25 Caso paradigmático es la creación de la Agencia Española de Seguridad Alimentaria (Ley 11/2001, de 5 de julio). Los motivos que abonan su aprobación son «(E)l carácter intersectorial, la naturaleza multifactorial y la indudable complejidad de la seguridad alimentaria». El artículo 4 de la Ley contempla la creación de un Comité Científico que tiene entre sus funciones coordinar los trabajos de los grupos de expertos que realicen actividades de evaluación de riesgos en el marco de las actuaciones de la Agencia.

26 Vid. J. Esteve Pardo, Técnica, riesgo y Derecho, op. cit., pp. 39-40. 
ve en el momento en que aquellas sobrepasan su propio espacio adquiriendo eficacia frente a terceros y ganando relevancia pública.

Conviene con el fin de lograr una mejor comprensión del tema, hacer tres apuntes. 1) En primer lugar, no es innecesario señalar que es en el ámbito de los llamados organismos de normalización -y no en otro- donde la norma técnica encuentra su foro de discusión, definición y, en su caso, aprobación. Ese campo, por lo demás, resulta hoy claramente supranacional y, en la práctica, extraño a una participación de los poderes públicos. En cambio, sí es destacable el papel que en la Europa comunitaria esos mismos poderes públicos han ido atribuyendo a la normalización. De este modo, desde instancias europeas, se ha fomentado el establecimiento de marcos jurídicos y financieros estables en aras de un desarrollo progresivo de aquella actividad en los ámbitos nacional y europeo ${ }^{27}$.

2) Tampoco carece de interés advertir de que la norma técnica -a diferencia de la norma jurídica- no busca una legitimación política y por ende social, sino aquella que le otorga el consenso hallado para su elaboración dentro de la comunidad científico-técnica. Ello no excluye, por supuesto, que dentro del ámbito institucional jurídico-político se elaboren regulaciones técnicas. De hecho, y conviene recordarlo, en nuestro país la actividad de normalización estuvo, hasta no hace mucho tiempo, sólidamente anclada en las estructuras administrativas ${ }^{28}$. Actualmente esto ya no es así, en España, al igual que en otros Estados europeos, la elaboración de normas técnicas stricto sensu corresponde a esos ya citados organismos de normalización que, por regla general, se configuran como entidades privadas sin ánimo de lucro.

3) En tercer lugar, hay que hacer también una previa y clara precisión terminológica. Por normas técnicas cabe entender aquellas especificaciones técnicas de adopción voluntaria, elaboradas por entidades reconocidas de carácter sectorial o multisectorial y de ámbito nacional, supranacional o internacional ${ }^{29}$. Existe, pues, una distinción entre nor-

27 En este sentido, el Consejo de la Unión Europea ha reiterado recientemente «la necesidad de que las Autoridades Públicas reconozcan la importancia estratégica de la normalización, en particular mediante el mantenimiento de un marco jurídico, político y financiero estable y transparente en el que la normalización pueda evolucionar más, y de que los organismos nacionales de normalización continúen apoyando el funcionamiento de la infraestructura europea y el logro de los objetivos europeos comunes», vid. Conclusiones del Consejo, de 1 de marzo de 2002, sobre la normalización, DO C 66, de 15 de marzo de 2002, p. 1.

28 Resulta aquí inexcusable referirse al trabajo de Francisco SosA WAGNER «La legalidad de la fijación de normas técnicas de calidad y otras cuestiones», $R A P, \mathrm{n}^{\circ}$ 84, 1977, pp. 661-670.

29 La propia Ley 21/1992, de Industria, nos ofrece esta definición en su artículo 8.3: «Norma: La especificación técnica de aplicación repetitiva o continuada cuya observancia no es obligatoria, establecida con participación de todas las partes interesadas, que aprueba un Organismo reconocido, a nivel nacional o internacional, por su actividad normativa». La naturaleza privada de este tipo de organismos no aparece en la Ley de Industria pero sí en el Reglamento de la Infraestructura para la Calidad y la Seguridad Industrial (RICSI) contenido 
mas técnicas y normas técnicas reglamentarias integrantes del ordenamiento jurídico. Estas últimas constituyen una auténtica categoría heteróclita de prescripciones técnicas que se caracterizan por su carácter obligatorio. Por el contrario, las normas técnicas conforman una (auto)regulación de origen privado y adopción voluntaria que se configura como un auténtico sistema dotado de sustantividad propia y, bien puede decirse, se sitúa extramuros del Derecho. No obstante, y ahí radica el quid de la cuestión, la norma técnica constituye hoy día parte casi indisociable del contenido de aquellas normas jurídicas de naturaleza técnica ${ }^{30}$. Por este motivo, la relación entre ambos tipos de normas debería observarse desde la perspectiva de dos ordenamientos o sistemas, dotados de sus referencias y modos propios de validez ${ }^{31}$.

\section{LA NORMA TÉCNICA EN EL DERECHO ADMINISTRATIVO ESPAÑOL}

\section{ACTO ADMINISTRATIVO Y NORMA TÉCNICA}

En España, a diferencia de otros países (p. ej. Francia y Bélgica), no existe la posibilidad de asimilar las normas técnicas aprobadas por la Asociación Española de Normalización y Certificación (AENOR) ${ }^{32}$ a un acto administrativo o a otro tipo de manifestación de la actividad administrativa. La inexistencia de jurisprudencia en este tema, así como

en el RD 2200/1995, de 28 de diciembre. El artículo 8 del RICSI establece que «Los Organismos de normalización son entidades privadas sin ánimo de lucro, cuya finalidad es desarrollar en el ámbito estatal las actividades relacionadas con la elaboración de normas, mediante las cuales se unifiquen criterios respecto a determinadas materias y se posibilite la utilización de un lenguaje común en campos de actividad concretos».

${ }^{30}$ La normalización es un manifiesto ejemplo de autorregulación. Ésta supone una complejidad social compuesta por diferentes sistemas cada uno de los cuales puede establecer normas o códigos de conducta de referencia. Estos sistemas autorreferenciales de diversa índole (económicos, éticos, técnicos, ambientales...) y dotados de sus propias estructuras terminan por contactar entre sí. El Derecho, el ordenamiento jurídico constituye uno de esos sistemas y, en mi opinión, el más importante pues es el medio que hace posible el perfecto fluir de la autorregulación. Vid. H. WILLKE, Ironie des Staates. Grundlinien einer Theorie des Staates polyzentrischer Gesellschaft, Suhrkamp, Francfort del Meno, 1992, p. 186 y ss. Sobre el tema de la autorregulación véase la reciente monografía de José ESTEVE PARDO Autorregulación. Génesis y efectos, Aranzadi, 2002. También, M. DaRnaculleta Gardella, Derecho administrativo y autorregulalación. La autorregulación regulada. Tesis doctoral inédita. Universitat de Girona, 2002.

31 Esta idea se encuentra singularmente desarrollada desde el ámbito de la sociología. Las principales aportaciones y su relevancia para el Derecho público han sido analizadas por J. Esteve PARDO en la citada obra Autorregulación. Génesis y efectos, especialmente p. 30 y ss.

32 AENOR es una asociación privada, reconocida desde el año 1986 por el antiguo Ministerio de Industria y Energía como entidad para desarrollar tareas de normalización y certificación. Desde entonces AENOR ha venido realizando, en la práctica de forma exclusiva, las actividades relacionadas con la elaboración de normas técnicas. Vid. M. TARRÉS VIVES, «Las nuevas referencias en el Derecho industrial: acreditación y normalización», cit., p. 147 y ss. 
el hecho de encontrar la norma técnica su origen en una asociación privada, atestiguarían esa imposibilidad.

Como principio, los actos administrativos deben emanar de una entidad pública, si bien cabe la posibilidad de que los particulares puedan dictarlos ${ }^{33}$. Para ello es necesario que entre el particular y la Administración exista una especial relación. La misma acostumbra a surgir a partir de una concesión de servicio. Éste sería, por ejemplo, el caso contemplado en el artículo 184 del Reglamento general de la Ley de Contratos de las Administraciones Públicas, en el que la delegación de determinadas facultades hacia el concesionario le permiten poder dictar actos que podrán ser recurridos ante la Administración. No es éste el caso de los organismos de normalización, cuya actividad no tiene en el RD 2200/1995 (RICSI) ${ }^{34}$ la consideración de actividad administrativa, sino de actividad privada sujeta a regulación. Por su parte, desde el ámbito judicial, concretamente en el Tribunal Supremo, la atención sobre las normas UNE ha sido ocasional, y en ningún caso su tratamiento ha constituido la ratio decidendi del asunto ${ }^{35}$.

Muy diferente resulta, en cambio, el caso francés donde la norma elaborada por su organismo de normalización (Association Française de Normalisation-AFNOR) sí tiene la consideración de acto administrativo $^{36}$. La jurisprudencia del Conseil d'État ha venido admitiendo desde

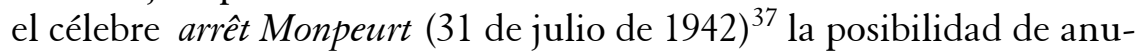
lar actos emanados de organismos privados -en ese caso previstos legalmente- si éstos ejercen su actividad en el marco del servicio público. Pues bien, en el caso de AFNOR, el Decreto de 26 de enero de 1984 la inviste de las prerrogativas de puissance publique en razón de la misión de servicio público que tiene encargada. Entre esas prerrogativas se

33 Vid. J. A. García-Trevijano Fos, Los actos administrativos, Civitas, Madrid, $2^{\mathrm{a}}$ ed., 1991, pp. 96-97.

34 Reglamento para la calidad y la seguridad industrial (BOE de 6 de febrero de 1996). Modificado por el RD 411/1997 (BOE de 26 de abril de 1997).

35 Por ejemplo, en la STS de 22 de enero de 1998 (Sala 3ª . Ar. 916). Esta sentencia trae causa en la impugnación «por ser contraria a principios técnicos y legales» de una Instrucción Técnica aprobada mediante Real Decreto por el a la sazón Ministerio de Obras Públicas y Transportes.

36 Vid. Franck Gambelli, Aspects juridiques de la normalisation et de la réglementation technique européenne, Éd. Eyrolles, París, 1994, p. 79 y ss.

37 Sentencia ampliamente tratada por T. R. FERNÁNDEZ RODRíGUEZ en su obra Derecho Administrativo, Sindicatos y Autoadministración, IEAL, Madrid, 1972, pp. 39-58. Posterior jurisprudencia del Consejo de Estado ha reconocido abiertamente la posibilidad de que personas de Derecho privado puedan adoptar decisiones constitutivas de un acto administrativo. Se trata, especialmente, del arrêt «Magnier», de 13 de enero de 1963 en el que el Conseil d'État establece que los organismos que constituyen «un organisme professionel de droit privé» y a los cuales se les aplica la reglamentación económica están dotados «d’un pouvoir de décision qui constitue une prérogative de puissance publique», de tal modo que sus decisiones ofrecen el carácter de un acto administrativo. 
cuenta la atribución al Consejo de administración de AFNOR de la potestad de homologar sus normas (con anterioridad tal función correspondía al ministro competente). AFNOR es, además, una asociación privada sometida a una estricta tutela administrativa. El carácter de servicio público de la normalización en Francia y la distinción entre norma «acto privado» y norma «acto administrativo» ha sido confirmada en dos importantes resoluciones. Así, en el caso «Conchyliculture» ${ }^{38}$ se afirma el carácter de acto administrativo reglamentario que tienen las normas técnicas homologadas por el Consejo de administración de AFNOR por delegación ministerial. En el arrêt «Textron» ${ }^{39}$, por su parte, se afirma el carácter estrictamente privado de las normas registradas por $\mathrm{AF}$ NOR y no homologadas. En ambas sentencias el Conseil d'État no refiere un criterio orgánico sino funcional al examinar, en cada caso, cuáles son las facultades de que hace uso el organismo de normalización.

\section{REGLAMENTO Y NORMA TÉCNICA. LA REGULACIÓN DE LA TÉCNICA POR EL ORDENAMIENTO JURÍDICO: PRINCIPIO DE LEGALIDAD Y REGLAMENTO INDEPENDIENTE}

La Ley 21/1992, de Industria, y, más concretamente, el RD 2200/1995 (RICSI), marcan un antes y un después en el tema de la normalización. Hasta ese momento la creación de normas técnicas en el seno de la Administración era una constante. Esas normas técnicas encontraban su cauce de expresión a través del reglamento. En este sentido, BAÑO LEÓN había señalado a las normas técnicas como un ámbito propicio al reglamento independiente -aquel que se dicta sin habilitación legal de ningún tipo y en virtud de la propia competencia reglamentaria de la Administración ${ }^{40}$; «un campo -añadía- de decisiva importancia económica, pero que apenas ha suscitado interés doctrinal» ${ }^{41}$. En aquel momento la normalización encontraba su regulación en el RD 1614/1985, de 1 de agosto, por el que se ordenaban las actividades

\footnotetext{
38 Conseil d'État, 14 de octubre 1991.
}

39 Conseil d'État, 17 de febrero 1992.

${ }^{40}$ Véase J. Ma BAÑo LEÓN, Los límites constitucionales de la potestad reglamentaria (Remisión normativa y reglamento independiente en la Constitución de 1978), Civitas, Madrid, especialmente p. 175 y ss.

41 Ibidem, p. 211. El capítulo de esta obra relativo a los reglamentos independientes se reproduce en su trabajo posterior «Los ámbitos del reglamento independiente», en Estudios sobre la Constitución Española (Homenaje al Profesor García de Enterría), Civitas, Madrid, 1991, vol. I, pp. 421-453. Sin embargo, las palabras que dan inicio al apartado que se refiere a las reglamentaciones técnicas resultan más ilustrativas que las arriba transcritas, dicen así: «El reglamento independiente hace tiempo que sentó sus reales en un campo que en nuestro país la doctrina apenas ha cultivado: el de las normas técnicas» (p. 444). 
de normalización y certificación. El artículo 1.2 de esta disposición hacía mención de hasta tres tipos de normas: 1) «Norma», como especificación técnica que era aprobada por una institución reconocida con actividades de normalización, para su aplicación repetida o continua, y cuya observancia no era obligatoria; 2) «Norma Española», toda norma que hubiese sido aprobada por el IRANOR, antes de la entrada en vigor del RD 1614/1985; las que aprobase con el indicativo «UNE» el Ministerio de Industria y Energía, así como las que surgiesen de las Asociaciones previstas en el Real Decreto - caso de AENOR- ${ }^{42}$, en las que también figuraría el anagrama «UNE» indicativo de «Una Norma Española»; 3) «Norma Oficial», era aquella «Norma Española» que se incorporaba al ordenamiento jurídico, para su aplicación en actuaciones técnicas de las Administraciones, prevaleciendo sobre otras normas técnicas existentes en el mismo campo ${ }^{43}$. Se establecía, además, la publicación íntegra de estas «normas oficiales» en el Boletín Oficial del Estado, y su declaración como tales por Orden de la Presidencia del Gobierno. Finalmente, se contemplaba la existencia de los «reglamentos técnicos» que consistían en especificaciones técnicas, con inclusión de las disposiciones administrativas aplicables, cuya observancia resultaba obligatoria.

Los cambios legales introducidos posteriormente en el ámbito de la normalización han supuesto la desaparición de las referidas «normas oficiales». En la actualidad las únicas normas técnicas reconocidas son las aprobadas por AENOR cuya publicación en el $B O E$ no se extiende al contenido, sino meramente a su referencia. Respecto a los reglamentos técnicos los mismos siguen siendo aprobados, constituyendo una constante la remisión que desde ellos se hace a normas técnicas.

Lo cierto es, sin embargo, que los problemas apuntados por BAÑO LEÓN a inicios de los años noventa se habrían visto acrecentados una década después. Efectivamente, la conversión de la norma técnica en «norma oficial» significaba convertir aquélla en norma reglamentaria. La cuestión que entonces se suscitaba, y que es atinadamente tratada por este autor, era la armonización entre la exigencia de reserva de ley

42 El Instituto Español de Racionalización y Normalización -antecedente directo de AENOR- era un organismo adscrito al Consejo Superior de Investigaciones Científicas, dependiente, a su vez, del Ministerio de Educación y Ciencia. Hasta el año 1985, el IRANOR fue el único organismo multisectorial de normalización; el mismo se encargaba de la publicación de las normas UNE y de la representación española en los foros internacionales. Por consiguiente, hasta bien entrada la década de los ochenta la normalización se desarrolla como una función administativa y con la única aportación de fondos públicos.

43 El artículo 9 del RD 1614/1985 establecía que podía conferirse carácter oficial a una norma cuando lo aconsejase alguna de las razones siguientes: «a) La racionalización y ordenación de las compras públicas; b) La necesidad de oficializar procedimientos de ensayo o medida, con el fin de ordenar sectores y facilitar la inspección administrativa; c) Las exigencias de tipo sanitario o medio-ambiental, en cuanto a los procedimientos para determinar composiciones o porcentajes de elementos, sustancias o productos». 
DA-2003, núms. 265-266. MARC TARRÉS VIVES. Las normas técnicas en el Derecho Administrativ...

-ante unas limitaciones al libre comercio por razones técnicas-y las características reglamentarias de aquellas normas. Tal armonización sólo resultaría posible, según el citado autor, mediante la técnica de las cláusulas generales, «en el bien entendido que debe quedar reservado a la ley los aspectos básicos del procedimiento que permitan su promulgación y la participación en su elaboración de los sectores afectados así como las reglas que aseguran la posición jurídica de los particulares ante las mismas ${ }^{44}$. De este modo, siendo perfectamente asumible que el contenido de la norma técnica se integre en una norma reglamentaria, resulta, sin embargo, necesario que su imposición obligatoria se contemple en una ley previa ${ }^{45}$. Tal cuestión habría sido parcialmente solventada con la promulgación de la Ley 21/1992, de Industria.

La conclusión extraída por BAÑO LEÓN de la anterior regulación sobre la normalización es lógica: las reglamentaciones técnicas sólo pueden ser objeto de un reglamento independiente si su contenido no es obligatorio, atribuyéndoles el carácter de meros dictámenes periciales anticipados. Es decir, el de simples reglas profesionales no vinculantes para el juez pero imprescindibles para la interpretación de la parte dispositiva de la norma reglamentaria ${ }^{46}$. Cabe indicar que este planteamiento sigue, en muy buena medida, la distinción que en Alemania se realiza entre disposiciones administrativas generales (Allgemeine Verwaltungsvorschriften) y disposiciones reglamentarias (Rechtsverordnung). Las primeras equivaldrían, en cierto modo, a lo que en nuestro ordenamiento jurídico llamamos circulares o instrucciones ${ }^{47}$ y, por tanto, no tendrían el carácter de norma coactiva. Sin embargo, el régimen jurídico de las circulares no es cuestión del todo pacífica en Alemania. Así, en materias técnicas se habría admitido por la jurisprudencia el ca-

44 Vid. J. Ma BAÑo LEÓN, Los límites constitucionales de la potestad reglamentaria, op. cit., p. 213.

45 En este sentido BAÑo LEÓN realiza la siguiente consideración: «A nadie se le oculta, desde luego, la necesidad de estas reglas y aun de que sean aprobadas por norma reglamentaria. Pero esta necesidad no justifica el desconocimiento del principio de reserva. Respetarlo es posible acudiendo a la ya aludida técnica de la remisión de carácter general. Ninguna razón hay para que el legislador no pueda prever al menos para el futuro las garantías básicas de estas normas. El hecho de que no exista ninguna ley que regule el régimen jurídico básico de unas normas con clara incidencia en la actividad económica general del país es el mejor argumento para esperar que el legislador sea en el futuro más sensible y regule esta cuestión», ibidem, p. 214. En el mismo sentido E. MALARET, en «Una aproximación jurídica al sistema español de normalización de productos industriales», $R A P, \mathrm{n}^{\circ} 116,1988, \mathrm{p} .335$.

46 Ibidem, p. 215.

47 Sobre la naturaleza jurídica de instrucciones y circulares véase: M. BAENA DEL ALCÁZAR, «Instrucciones y Circulares como fuente del Derecho Administrativo», RAP, ${ }^{\circ}$ 48, 1965 , p. 107 y ss.; J. A. Santamaría PaStor, Fundamentos de Derecho Administrativo, Ceura, Madrid, 1988, pp. 727 y ss.; M. MORENO REBATO, «Circulares, Instrucciones y Órdenes de servicio: Naturaleza y régimen jurídico», $R A P, \mathrm{n}^{\circ} 147,1998$, p. 159 y ss. 
rácter vinculante de las disposiciones administrativas generales, si bien bajo ciertas modulaciones. Significativa en este sentido es la sentencia de la Sala de lo Contencioso del Tribunal Supremo (Bundesverwaltungsgericht) de 19 de diciembre de 1985, relativa a la central nuclear de $\mathrm{Wyh}^{48}$, en la que se reconoció expresamente la existencia de disposiciones administrativas que «concretan una norma jurídica» que se impone a los Tribunales administrativos en los límites fijados por la norma que ha de concretarse. En todo caso, como ha reconocido el propio Tribunal Constitucional (Bundesverfassungsgericht) la referida sentencia constituye una excepción a la regla de que «las circulares (...) no son leyes en el sentido del apartado 3 del artículo 20 y del apartado 1 del artículo 97 de la Ley Fundamental (en el sentido de que la Ley se impone al Juez)» ${ }^{49}$.

Volviendo a la Ley española de Industria, ésta ha sancionado la existencia de ámbitos cuya regulación ofrece una alta complejidad técnica y para los que la ley no resulta el instrumento normativo adecuado. En este sentido, la habilitación al Gobierno contenida en el artículo 12.5 de la Ley de Industria ${ }^{50}$ sería una opción del legislador en el reconocimiento de una potestad normativa autónoma del Consejo de Minis$\operatorname{tros}^{51}$ respecto a reglamentaciones técnicas. Posibilidad que, en mi

48 BverwGE 72, p. 300 y ss., publicada también en $D O ̈ V, 1986$, p. 431 y ss.

49 BverfGE 78 (31.5.1988), p. 227, publicada también en $N J W$, 1989, p. 666 y ss.

50 «Los Reglamentos de Seguridad Industrial de ámbito estatal se aprobarán por el Gobierno de la Nación, sin perjuicio de que las Comunidades Autónomas, con competencia legislativa sobre industria, puedan introducir requisitos adicionales sobre las mismas materias cuando se trate de instalaciones radicadas en su territorio». La existencia de este precepto daría respuesta a quienes, de forma unánime, exigen una habilitación legal para la aprobación de los reglamentos de seguridad por el Gobierno. En este sentido, ÁlVAREZ GARCía escribe: «(L)a regulación que la Ley de Industria hace de la seguridad industrial contiene, en mi opinión, la cobertura legal mínima necesaria exigible para que puedan dictarse válidamente reglamentos técnicos de seguridad sin que éstos violen el principio de reserva de ley...», La normalización industrial, op. cit., p. 264 y pp. 113-122. Postura contraria es la mantenida por CARRILLO DONAIRE quien considera que «la Ley de Industria se limita a listar el elenco de previsiones que han de contener los citados Reglamentos, pero no aporta dato alguno de cómo han de materializarse, con qué contenido mínimo, qué garantías han de observarse, ni qué efectos conllevan en cada caso», concluyendo que «(M)ás bien pudiera decirse, a tenor de la inconcreción legal que gobierna la materia, que donde verdaderamente opera la reserva de ley que pretende cumplimentar la LI es en lo que calla, más que en lo que dice. Verdaderamente, el único en el que existe un parámetro cierto con el que contrastar la legalidad de los Reglamentos de Seguridad es en el de los posibles contenidos de los mismos a los que no se refiere la LI, hasta el punto de poder afirmar que la reserva se cumplimenta aquí de forma más efectiva por omisión que por provisión legislativa», El Derecho de la seguridad y de la calidad industrial, op. cit., pp. 331-332. Este autor aborda un exhaustivo examen sobre la potestad reglamentaria y sus presupuestos legitimadores en la materia de seguridad industrial (pp. 314-338).

51 De acuerdo con el art. 1.3 de la Ley del Gobierno 50/1997, de 27 de noviembre, «(L)os miembros del Gobierno se reúnen en Consejo de Ministros (...)», y según el art. 5.1 «(A)l Consejo de Ministros, como órgano colegiado del Gobierno, le corresponde: h) Aprobar los reglamentos para el desarrollo y la ejecución de las leyes, previo dictamen del Consejo de Estado, así como las demás disposiciones reglamentarias que procedan». 
opinión, no estaría vedada constitucionalmente ${ }^{52}$. Es cierto, sin embargo, que la aprobación de la Ley de Industria habría dado respuesta a los planteamientos prácticamente unánimes que desde la doctrina venían exigiendo la necesidad de una disposición legal que autorizase al Gobierno a imponer las limitaciones que implican los reglamentos de seguridad. Ahora bien, no es menos cierto que la existencia formal de las previsiones contenidas en la mencionada ley (especialmente en sus artículos 12 y 13) no llegan a alcanzar relevancia sustantiva. Con ello quiero significar que la aprobación de la Ley de Industria no ha supuesto, a efectos prácticos, ninguna novedad con relación a la situación anterior, sino el de habilitar una remisión reglamentaria ${ }^{53}$ que será, en verdad, donde se contendrá toda la regulación de seguridad industrial ${ }^{54}$.

La legitimación del Gobierno en el ejercicio de la potestas normandi supondría que el reglamento técnico -aprobado mediante Real Decreto- es el título habilitante de otros actos jurídico-administrativos de naturaleza normativa y también de contenido técnico, como pueden ser las órdenes ministeriales. En este sentido, los diferentes tipos de regla-

52 En este sentido la STS de 29 de octubre de 1985 (Ar. 5328), en la que se reconoce «la sola existencia de los reglamentos es indicativa de su necesidad en la Constitución española (art. 97); necesidad que se acrecienta cuando, como en este Real Decreto sucede, se trata de una auténtica regla técnica, alejada de los conocimientos de la mayoría de los componentes de las Cámaras legislativas (...)», añadiendo «que existen materias, como en las técnicas..., en las que se puede pensar con todo el convencionalismo que se quiera, en una materia reservada al reglamento»-cursiva entrecomillada en el texto-. Esta sentencia es comentada por BAÑo LEÓN quien critica el razonamiento del TS alegando que prescinde del principio de reserva de ley, cuyo respeto es posible acudiendo a la técnica de la remisión de carácter general. «Ninguna razón hay -expone este autor-para que el legislador no pueda prever al menos para el futuro las garantías básicas de estas normas. El hecho de que no exista ninguna ley que regule el régimen jurídico básico de unas normas con clara incidencia en la actividad económica general del país es el mejor argumento para esperar que el legislador sea en el futuro más sensible y regule esta cuestión», en Los límites constitucionales de la potestad reglamentaria, op. cit., p. 214. La solicitud hecha por este autor de una ley previa que legitimase los reglamentos técnicos encontraría su respuesta en la posterior Ley 21/1992, de Industria.

53 En este sentido conviene considerar la clasificación que Manuel REBOLLO PUIG realiza de los reglamentos en relación a la ley. Este autor distingue cuatro categorías distintas: a) reglamento complementario y habilitado; b) reglamento complementario espontáneo; c) reglamento remitido o delegado; d) reglamento independiente. Dicha clasificación atiende a dos criterios diferentes, por un lado, según cuenten o no con una habilitación legal expresa; por otro, según su contenido material sea desarrollo de la regulación contenida en la ley o no. Así, el reglamento remitido o delegado es definido como aquél «habilitado por la ley, pero cuyo contenido no desarrolla una previa regulación de aquélla que se limite a remitir la ordenación material al futuro reglamento», en «El ejercicio de potestades normativas y el Consejo de Estado», Documentación Administrativa, no 244-245, 1996, p. 175.

54 En este sentido, CARRILlo DONAIRE reconoce que en materia de seguridad industrial el grado de vinculación entre ley y reglamento se reduce al mínimo, pudiendo hablarse de reglamentos «enganchados» a aquélla en virtud de la especialidad eminentemente técnica de la materia. Así, concluye, «en esta materia, la ley no atiende a un criterio de máxima previsibilidad normativa, sino a la visión más flexibilizada del principio de reserva», en El Derecho de la seguridad..., op. cit., p. 327. 
mentaciones técnicas (instrucciones técnicas ${ }^{55}$, normas básicas de la edificación ${ }^{56}$, reglamentaciones técnico-sanitarias ${ }^{57}$ ) son aprobadas por el Gobierno mediante un Real Decreto en el que se acostumbra a autorizar $^{58}$ que el Ministro competente pueda, a través de una Orden ${ }^{59}$, modificar o actualizar su contenido ${ }^{60}$. Esta delegación ${ }^{61}$ o habilitación del

55 Bajo la denominación de «Instrucciones Técnicas Complementarias» (ITC) se encuentran una serie de reglamentaciones sobre determinados productos e instalaciones industriales. Las ITC, propuestas por el Ministro competente, acostumbran a constar como anexo en el Real Decreto aprobado por el Consejo de Ministros. Por ejemplo, la ITC MI-IP 03 «Instalaciones petrolíferas para uso propio», aprobada por el RD 1427/1997, de 15 de septiembre; la ITC MIE-APQ-006, «Almacenamiento de líquidos corrosivos», aprobada por el RD 1830/1995, de 10 de noviembre. Existen también instrucciones técnicas bajo la mera denominación de Instrucciones, es el caso de la Instrucción para el proyecto y la ejecución de forjados unidireccionales de hormigón armado o pretensado (EF-96), aprobada por el RD 2608/1996, de 20 de diciembre.

56 La Normas Básicas de la Edificación (NBE) fueron creadas por el RD 1650/1977 del Ministerio de la Vivienda y son definidas como «normas que, a partir del conocimiento científico y tecnológico, establecen las reglas necesarias para su correcta aplicación en el proyecto y ejecución de los edificios. Tienen como finalidad fundamental defender la seguridad de las personas, establecer las restantes condiciones mínimas para atender las exigencias humanas y proteger la economía de la sociedad». La aprobación de la Ley 38/1999, de 5 de noviembre, de ordenación de la edificación (LOE), ha supuesto la aplicación transitoria de las NBE hasta la aprobación por el Gobierno, prevista en mayo de 2002, del Código Técnico de la Edificación (CTE), marco normativo que establecerá las exigencias básicas de calidad de los edificios y de sus instalaciones (Disposición Final segunda en relación con el artículo 2, apartados 1.b) y 1.c) de la Ley. Esta misma Disposición enumera un total de siete NBE -p. ej. NBE FL-90 «Muros resistentes de fábrica de ladrillo»-que seguirán aplicándose hasta la aprobación del CTE). El CTE tendrá carácter de legislación básica y deberá actualizarse periódicamente conforme a la evolución de la técnica y las demandas de la sociedad. Con carácter general, véase J. GONZÁLEZ PÉREZ, Comentarios a la Ley de Ordenación de la Edificación, Civitas, Madrid, 2000; J. SERRA MARía-TOMÉ, «El Código Técnico de la Edificación en la LOE», Revista de Derecho Urbanístico y Medio Ambiente, abril-mayo 2000, pp. 49-66.

57 Por ejemplo, la Reglamentación Técnico-Sanitaria de Lejías aprobada por el RD 3360/1983, de 30 de noviembre.

58 Sobre el carácter equívoco que ofrece el uso del término «autorización» con relación a la habilitación reglamentaria, véase R. MARTíN MATEO, «La degradación normativa de las disposiciones reglamentarias. Su contraste con la Ley Orgánica del Estado», $R A P$, nº 51, 1966, pp. 324-325.

59 Sobre la potestad reglamentaria de los Ministros, véase J. A. SANTAMARÍA PASTOR, Fundamentos de Derecho Administrativo, op. cit., p. 760; E. GARCÍA DE ENTERRÍA y T. R. FERNÁNDEZ, Curso de Derecho Administrativo, Madrid, Civitas, 1997, t. I, p. 178. En ambos casos, se afirma que la potestad reglamentaria de los Ministros precisa de una habilitación especial por parte del titular primario y general de la misma que es el Gobierno. Más concretamente, los últimos autores citados consideran que «no es una potestad reglamentaria general (que el art. 97 de la Constitución reconoce sólo al Gobierno), sino una facultad necesitada en cada caso de una habilitación especial».

60 Así, la Disposición Final segunda del Reglamento de Instalaciones Térmicas en los Edificios (ITE), aprobado mediante el Real Decreto 1751/1998, de 31 de julio, establece que: «Se autoriza a los Ministros de Industria y Energía y de Fomento para que, conjuntamente, o en el ámbito de sus respectivas competencias dicten las disposiciones necesarias (...) para la actualización y revisión de las Instrucciones Técnicas Complementarias ITE».

61 Véase V. Álvarez García, La normalización industrial, op. cit., pp. 168-171. Este autor considera que a tenor de lo previsto en el artículo 12 de la Ley de Industria se «atribuye la competencia para adoptar los reglamentos técnicos en materia de seguridad indutrial al Gobierno sin contener ninguna cláusula habilitante para poder subdelegar fuera de él esta competencia. Por ello -añade-, toda subdelegación normativa del Go- 
DA-2003, núms. 265-266. MARC TARRÉS VIVES. Las normas técnicas en el Derecho Administrativ...

Gobierno a órganos inferiores -concretamente Ministros- para la elaboración de reglamentaciones técnicas plantea, por parte de la doctrina, otro grave escollo, al considerarse que las habilitaciones hechas a los Ministros en los reglamentos técnicos aprobados por el Gobierno superan con creces los límites de la potestad reglamentaria ministerial. En este sentido se afirma que el reconocimiento de una potestad reglamentaria ejecutiva sólo corresponde al Consejo de Ministros y no cabe deferir la misma en otros órganos. Sólo en el caso de que fuera el legislativo quien expresamente hubiera previsto esa delegación normativa podría aceptarse una regulación reglamentaria per saltum que obviara el primer escalón jerárquico de las disposiciones generales de la Administración $^{62}$. Más matizadamente, IZQUIERDO CARRASCO admite que la atribución de potestad reglamentaria a los Ministros puede ser tanto por ley como por reglamento aprobado por el Consejo de Ministros. De todos modos, reconoce este autor, deberá examinarse caso por caso el cómo, cuándo y sobre qué materias van a ejercer los Ministros esa potestad reglamentaria habilitada ${ }^{63}$.

La controversia en torno al alcance de la habilitación reglamentaria hecha por el Consejo de Ministros a órganos inferiores se produce especialmente al tratar de definir su alcance. Así, se argumenta que en el caso de una orden ministerial existiría una ausencia de legitimidad si aquélla tuviese una eficacia vinculante ad extra (p. ej., una reglamentación técnica obligatoria para el fabricante de un determinado producto). En mi opinión, sin embargo, la habilitación mediante Real Decreto a una norma reglamentaria de rango inferior para la definición o establecimiento de prescripciones técnicas no sólo no me parece legítima, sino necesaria. Los diferentes mandatos constitucionales que definen el modelo de Estado social y democrático no pueden alcanzar plena eficacia si el marco de actuación administrativa se ciñe únicamente a legitimidad jurídica. Como bien advierte TORNOS, «(E)l Estado social de Derecho impone una legitimidad no exclusivamente legal o jurídica, sino también de resultados. La ley, o en sentido más amplio, el ordenamiento, no agota toda la legitimación de la actividad administrativa» ${ }^{64}$. Así, en lo que respecta al establecimiento de regulaciones técnicas, importa más la audiencia y participación de los sectores afectados que el rango o proce-

bierno a cualquier sujeto distinto de él mismo es ilegal. Es ilegal una habilitación por el Gobierno a un Ministro (...)», p. 171.

${ }^{62}$ Véase J. A. Carrillo Donaire, El Derecho de la seguridad y de la calidad industrial, op. cit., pp. 336-337.

63 Véase M. IZQUIERdo CARRASCO, La seguridad de los productos industriales, op. cit., Madrid, 2000, p. 212.

64 Joaquín TORNOS MAS, «El principio de legalidad en la doctrina jurídica española», Diritto Pubblico, $\mathrm{n}^{\circ} 1,1995$, p. 89. 
dencia de la norma en que se contienen las especificaciones técnicas. Por este motivo, no deja de ser un sinsentido mantener, por parte de los juristas, una rigidez ordenancista y aceptar, en cambio, el reenvío a normas técnicas privadas. En este sentido, la necesidad de una reserva de ley en lo que atañe a los reglamentos técnicos podría resultar una exigencia lógica en un contexto de absoluto monopolio jurídico-normativo-estatal en la definición de prescripciones técnicas ${ }^{65}$, pero no cuando esa función resulta no exclusiva del ordenamiento jurídico. Y ésta es la situación actual que, además, va acompañada de una progresiva disolución del carácter coactivo de las reglamentaciones técnicas. Efectivamente, estas reglamentaciones tienden, en la actualidad, no a una obligatoriedad, sino a lograr una adopción voluntaria por parte de sus destinatarios, para quienes el seguimiento de las reglamentaciones técnicas significa una presunción de cumplimiento con las cláusulas generales contenidas en los reglamentos técnicos elaborados por el Ejecutivo ${ }^{66}$. En ese nuevo modelo dejarían de existir de iure unas limitaciones que exigiesen la reserva de ley y la interdicción de una degradación normativo-jurídica en cuestiones técnicas.

Según se ha escrito anteriormente, el recurso a la técnica de la remisión de carácter general por parte de la ley hacia el reglamento es, sin duda, una propuesta perfectamente adecuada al planteamiento de que es el legislador quien habilita a la Administración para la elaboración de una normativa cuya evidente complejidad técnica la hace inadecuada para la ley. Ejemplo de esa remisión es la que realizaba el artículo 29 de la Ley 31/1982, de 18 de diciembre, de ordenación de las telecomunicaciones. Este precepto autorizaba al Gobierno para regular los equipos, aparatos, dispositivos y sistemas que hicieren uso del espectro

${ }^{65}$ Ello no excluye, por supuesto, que los reglamentos en los que se contengan especificaciones técnicas no deban seguir el procedimiento tipo de elaboración de diposiciones generales. Debe, pues, respetarse el principio de audiencia y participación de aquellas organizaciones o asociaciones que preceptivamente deban ser oídas en el trámite de elaboración de disposiciones generales. Sin embargo, corresponde en todo caso a la Administración elegir la opción técnica que considere más idónea. Decisión ciertamente discrecional en la que el control judicial no puede extenderse más allá de un examen conforme a las reglas de la sana crítica, en el que no deben confundirse imprecisiones técnicas con vicios de legalidad. En este sentido la STS de 22 de enero de 1998 (Sala 3 ${ }^{\mathrm{a}}$. Ar. 916) dice: «(E)n el ejercicio del poder de control atribuido a los Tribunales (art. 106. 1 de la CE) sobre la potestad reglamentaria y la legalidad de la actividad administrativa -por supuesto, incluida en esta última la actividad discrecional- no cabe, cuando de cuestiones exclusivamente técnicas se trata, sustituir el criterio de la Administración por el que la recurrente propugna con fundamento en unas consideraciones que, repetimos, no han demostrado la existencia de vicios de forma o fondo en las normas impugnadas».

66 Así, por ejemplo, en la Orden del Ministerio de Industria, de 24 de julio de 1992, que modifica la Instrucción Técnica Complementaria MI BT 026 del Reglamento Electrotécnico para Baja Tensión, establece que contra el riesgo de explosión o inflamación que suponen los materiales eléctricos podrá aplicarse, entre otros, el siguiente modo de protección: - Inmersión en aceite «O»: normas UNE 20326-70 y UNE 21-815-89, y alternativamente EN 50015, primera edición, de marzo de 1977, con enmienda de julio de 1979, o CEI primera edición de 1968. 
radioeléctrico. Al amparo de esta Ley se dictó el RD 1066/1989, por el que se estableció el procedimiento para la elaboración de las especificaciones técnicas. Ahora bien, tal situación sufre una modificación radical con la Ley 11/1998, de 24 de abril, General de Telecomunicaciones $^{67}$, disposición dictada al amparo de la legislación europea y en cuyo artículo 29 se leía: «La Comisión del Mercado de las Telecomunicaciones velará para que, en los acuerdos de interconexión, se tengan en cuenta las normas comunitarias que sean de aplicación. En defecto de éstas, fomentará la aplicación de las normas, de las especificaciones o de las recomendaciones que se aprueben por los organismos europeos o, a falta de éstas, de las adoptadas por los organismos internacionales de normalización. En ausencia de todas ellas, se tendrán en cuenta las normas nacionales» ${ }^{68}$. La remisión que en este caso se realiza no es a unas especificaciones técnicas contenidas en una norma jurídica, sino a una norma técnica en sentido estricto. Cabe señalar que la reciente aprobada Ley 32/2003, General de Telecomunicaciones, prevé en su artículo $15^{69}$ una redacción similar al citado artículo 29 de la ya derogada Ley 11/1998.

${ }^{67}$ BOE de 25 de abril de 1998.

68 Este artículo ha sido desarrollado por el artículo 5 del RD 1651/1998, de 24 de julio, que establece el Reglamento de interconexión y numeración. Dicho precepto establece que «la interconexión y el acceso a las redes deberán cumplir las especificaciones técnicas que se establezcan por el Ministerio de Fomento. En particular, dichas especificaciones técnicas y las interfaces de los puntos de interconexión, se ajustarán a las normas que se indiquen en el «Diario Oficial de las Comunidades Europeas». En defecto de tales normas, la Comisión del Mercado de las Telecomunicaciones fomentará el uso de las siguientes, con el orden de prelación siguiente: a) Las adoptadas por los siguientes organismos europeos de normalización reconocidos: el Instituto Europeo de Telecomunicación (ETSI), el Comité Europeo de Normalización y el Comité Europeo de Normalización Electrotécnica (CEN-CENELEC); b) Las internacionales adoptadas por la Unión Internacional de Telecomunicaciones (UIT), la Organización Internacional de Normalización (ISO) o la Comisión Electrotécnica Internacional (CEI); c) Las emanadas del organismo español de normalización: AENOR; d) Las especificaciones que cuenten con amplia aceptación en la industria y hayan sido elaboradas por los correspondientes organismos internacionales; e) Las especificaciones técnicas que se apliquen habitualmente en el mercado. Véase A. CARRASCO y A. I. MENDOZA «Interconexión y acceso a redes», en Comentarios a la Ley General de Telecomunicaciones (A. Arpón de Mendívil y A. Carrasco, dir.), Aranzadi, 1999, p. 461 y ss.

69 El artículo 15 de la Ley 32/2003 establece: «La Comisión del Mercado de las Telecomunicaciones, en los acuerdos de acceso e interconexión, fomentará el uso de las normas o especificaciones técnicas identificadas en la relación que la Comisión Europea elabore a tal efecto, que se publicarán en el «Boletín Oficial del Estado» cuando hayan sido declaradas de uso obligatorio, para garantizar la interoperabilidad de los servicios y para potenciar la libertad de elección de los usuarios.

En defecto de dichas normas, la Comisión del Mercado de las Telecomunicaciones fomentará la aplicación de las normas, especificaciones o recomendaciones que se aprueben por los organismos europeos o, en ausencia de éstas, por los organismos internacionales de normalización». 
DA-2003, núms. 265-266. MARC TARRÉS VIVES. Las normas técnicas en el Derecho Administrativ...

\section{LA PROBLEMÁTICA REMISIÓN A LA NORMA TÉCNICA DESDE LA NORMA JURÍDICA. LA REGULACIÓN DE LA TÉCNICA POR EL ORDENAMIENTO DE LA TÉCNICA}

Como se ha señalado, la norma técnica puede alcanzar significación jurídica cuando desde una norma del ordenamiento jurídico se hace remisión a ella. Esta posibilidad es frecuentemente usada tanto por el Derecho técnico como por el Derecho ambiental. Puede decirse que mediante la técnica de remisión el contenido de normas provenientes de organizaciones privadas pasa a adquirir los atributos de validez y eficacia propios de la norma jurídica.

Este tema ha sido objeto de especial atención en estos últimos años por parte de los administrativistas españoles ${ }^{70}$. La razón de este tratamiento obedece, de modo principal, a la relevancia adquirida en nuestro ordenamiento por las normas técnicas a partir de la política comunitaria de armonización técnica del llamado «nuevo enfoque». La adaptación de la legislación española a las previsiones europeas se ha dejado sentir de manera especial en la regulación industrial. En ese ámbito las reglamentaciones administrativas han dejado, en buena medida, de contener complejas prescripciones técnicas -que en su literalidad y amplia extensión consumían numerosas páginas de los boletines oficiales- para limitarse a declarar unas cláusulas generales de seguridad que encuentran su concreción a partir de la remisión que se realiza a las normas técnicas privadas. La ventaja más evidente que ofrece la aplicación de este planteamiento es la de garantizar una constante adaptación de la norma jurídica al estado de la técnica, mediante el uso, por parte principalmente de normas reglamentarias, de cláusulas remisoras. Cabe señalar que este fenómeno no es en absoluto novedoso. Las remisiones, principalmente desde reglamentos, a normas de origen privado han existido desde hace décadas ${ }^{71}$. Lo que sí resulta nuevo es la

70 Especialmente, J. Esteve PARdo, Técnica, riesgo y Derecho, op. cit., p. 153 y ss.; V. Álvarez García, La normalización industrial, op. cit., p. 181 y ss.; J. A. CARRILlo DONAIRE, El Derecho de la Seguridad y de la calidad industrial, op. cit., p. 393 y ss.; M. IZQUIERDO CARRASCO, La seguridad de los productos industriales (Régimen jurídico-administrativo y protección de los consumidores), op. cit., 2000, p. 245 y ss.

71

Como advierte IZQUIERDO CARRASCO, en la primera mitad del siglo XX se encuentran remisiones a documentos técnicos elaborados por entidades de prestigio, por regla general extranjeras, y que no necesariamente eran organismos de normalización. Este mismo autor refiere una Real Orden de 10 de febrero de 1931, en la que se disponía la adopción «como reglamento para los ensayos estáticos de prototipos de avión el Reglamento para la Construcción y Clasificación de Aeronaves en la parte relativa a ensayos del Bureau Veritas, Sociedad Internacional de Registros y Clasificación de Navíos y Aeronaves», así como la Orden de 28 de octubre de 1941 ( $B O E$ de 1 de noviembre), en la que se establecía: «sólo podrán usar la denominación de productos puros químicamente considerados los que cumplan las normas de pureza redactadas y recomendadas por el Comité de reactivos para análisis de la 
DA-2003, núms. 265-266. MARC TARRÉS VIVES. Las normas técnicas en el Derecho Administrativ...

generalización de esas remisiones y la eficacia que con ellas ganan las normas técnicas privadas. Por este motivo no es de extrañar que las objeciones hechas por los juristas a este tipo de normas radiquen principalmente en los problemas constitucionales de legitimación y legalidad que, como ha destacado ESTEVE PARDO, plantea la atribución desde el ordenamiento jurídico de eficacia vinculante a las normas técnicas privadas ${ }^{72}$. En suma, el resquemor de los publicistas ante la norma técnica deriva principalmente de su incompatibilidad con uno de los principios básicos del Estado de Derecho: el principio de legalidad.

A la vista de lo expuesto hasta ahora pueden constatarse dos hechos. En primer lugar que el imperio del Derecho ya no es efectivo en términos absolutos $^{73}$; y, en segundo término, corresponde a la Administración articular el modo en que se realizan las remisiones allende del ordenamiento jurídico y de las estructuras propias del Estado de Derecho. El fenómeno de la remisión por normas jurídicas a las normas técnicas elaboradas por los organismos privados de normalización plantea las dos cuestiones descritas.

La remisión por normas jurídicas a normas técnicas se justifica por varias razones; entre ellas destaca la imposibilidad del aparato administrativo de adecuar al estado de la técnica el conjunto de reglamentaciones técnicas, es decir, de evitar el desfase de la reglamentación. Ello justifica el recurso a conocimientos externos y, en concreto, a las normas técnicas elaboradas por organismos de normalización que, pese a su naturaleza privada, gozan también, de muy diversas maneras, de un reconocimiento público. La remisión a la norma técnica tiene, pues, por finalidad lograr la integridad de la norma jurídica o, dicho de otro modo, la norma técnica tiene un carácter completivo de la norma jurídica.

La técnica jurídica del reenvío es la que con propiedad nos permite estudiar lo que con carácter general viene en llamarse remisión legal -ley o, principalmente, reglamento- a normas técnicas. En aquélla se distingue entre el reenvío material o recepticio y el reenvío formal o remisión. El primero se caracteriza por incorporar la norma reenviada a la norma reenviante como si se tratase de una norma propia. Por este motivo, con total acierto, MARBURGER considera que en este caso nos encontramos ante una «abreviatura técnico-legislativa» ${ }^{74}$. En la prácti-

American Chemical Society, que se adopten como normas para su aplicación en España», en La seguridad de los productos industriales, op. cit., p. 246 en nota.

72 Vid. J. Esteve PARdo, Técnica, riesgo y Derecho, op. cit., p. 169.

73 Sobre este tema véase la obra de J. EsTEVE PARDO, Autorregulación. Génesis y efectos, op. cit.; también X. ARBÓs MARíN, «La crisis de la regulación estatal», Revista de Estudios Políticos, $\mathrm{n}^{\circ}$ 71, 1991, pp. 259-280.

74 Concretamente, una "gesetzgebungstechnische Abbreviatur des Normtextes", vid. P. Marburger, Die Regeln der Technik im Recht, Carl Heymans, Colonia, 1979, p. 387; tam- 
ca el reenvío recepticio supone que el reglamento hace remisión a una determinada versión de la norma técnica ${ }^{75}$, prescindiendo de las nuevas versiones que en su caso pudiese realizar el organismo de normalización. Diferente es, en cambio, el caso del reenvío formal o remisión, en el que una norma remite a lo dispuesto en otra ya existente. Aquí, la norma reenviante asume el contenido de la norma reenviada no en un sentido material, sino formal. Es decir, la norma reenviante asume en el momento de su aprobación el contenido presente de la norma reenviada, pero también el que ésta pueda tener en el futuro.

En síntesis, los dos casos descritos permiten distinguir entre: 1) el reenvío estático o recepticio de la norma técnica, y 2) el reenvío dinámico o remisión a la norma técnica. Junto a este tipo de reenvío de carácter directo existiría también 3) el reenvío indirecto a normas técnicas que actuaría a partir de la remisión mediante cláusulas generales contenidas en la norma jurídica.

En todos estos supuestos opera una auténtica relación entre dos ordenamientos distintos: por un lado, el ordenamiento jurídico; por otro, el ordenamiento de la técnica ${ }^{76}$. Ambos, conviene advertirlo, dotados de su propia sistemática.

bien B. Schünemann, «Las reglas de la técnica en el Derecho penal», en Anuario de Derecho Penal y Ciencias Penales, t. XLVII, fascículo III, 1994, p. 320.

75 Por ejemplo, el RD 3360/1983, de 30 de noviembre, mediante el que se aprueba la Reglamentación Técnico-Sanitaria de Lejías, establece en su Anexo I que los métodos analíticos para la determinación del cloro activo y la alcalinidad total serán los previstos en la norma UNE 55-528-77, parte I y III, y VI, respectivamente. Atendiendo a que las dos últimas indican el año de aprobación por el organismo de normalización, las posibles posteriores modificaciones de la norma técnica no incidirían en el contenido de la norma reglamentaria a menos que hubiera una posterior modificación de esta última. Otro ejemplo sería el de la Instrucción Técnica Complementaria MI-BT 044 del Reglamento Electrotécnico para Baja Tensión; la Orden del Ministerio de Industria y Energía de 30 de septiembre de 1980 (BOE de 17 de octubre) estableció como de obligado cumplimiento, entre otras, la norma UNE 20315-79, referente a bases de toma de correinte y clavijas para usos domésticos y análogos, incluyéndola en la relación de normas de la citada ITC. Posteriormente, en diciembre de 1994, AENOR aprobó la UNE 20-315-94, que introdujo significativas mejoras en relación a la versión precedente. Sin embargo, no fue hasta la Orden de 22 de noviembre de 1995 (BOE de 4 de diciembre) cuando se adaptó al progreso técnico la referida ITC, incorporándose la nueva versión de la norma UNE. Con carácter general la relación de normas UNE contenidas en reglamentos técnicos aprobados mediante RD son actualizadas mediante Orden del ministerio competente (p. ej. la Orden del Ministerio de Fomento, de 5 de julio de 1996 (BOE de 25 de julio), por la que se actualiza el apéndice de «Normas UNE de Referencia» del anexo del Real Decreto 1572/1990, de 30 de noviembre, que aprueba la norma básica de la edificación NBE QB-90 «Cubiertas con materiales bituminosos»). Los últimos casos descritos serían considerados por IZQUIERDO CARRASCO no como un supuesto de reenvío material o recepción, sino de reenvío formal sometido a previa aceptación. La justificación ofrecida por este autor radica en que de este modo se «simplificaría la calificación de la naturaleza jurídica de este tipo de resoluciones», en La seguridad de los productos industriales, op. cit., p. 251.

76 J. ESTEVE PARDO observa la pretendida configuración de un ordenamiento o paraordenamiento de la técnica al que, ciertamente, no son ajenas las instancias públicas nacionales y europeas, vid. Técnica, riesgo y Derecho, op. cit., p. 163; esta idea es desarrollada en su obra Autorregulación. Génesis y efectos, op. cit. En este sentido, IZQUIERDO CARRASCO reconoce también 
DA-2003, núms. 265-266. MARC TARRÉS VIVES. Las normas técnicas en el Derecho Administrativ...

\section{A) La remisión directa al ordenamiento de la técnica}

Según hemos señalado, la conexión entre la norma jurídica y la norma técnica puede ser mediante un reenvío directo que, en atención a su alcance, permite distinguir entre el reenvío recepticio y la remisión. Ambos ofrecen unas particularidades que parcialmente ya hemos descrito, ahora conviene observar su admisibilidad desde los postulados del Estado democrático y de Derecho. Debemos advertir de que, establecida de antemano la inclusión de la remisión como un supuesto de reenvío, en lo que sigue haremos uso preferente del término «remisión» por su aceptada generalización.

\section{a.1) El reenvío estático o recepticio a la norma técnica: el problema de la publicidad normativa}

La remisión estática o nominada ${ }^{77}$ consiste en una modalidad de recepción de la norma técnica por parte de la norma jurídica. Así, la norma técnica resulta explícitamente designada e identificada por sus datos externos (su título y número, año de aprobación o edición, etc.). Como se ha señalado, la fijación de la norma técnica comporta que las posteriores modificaciones de la normas no son aplicables si no se recogen en la norma jurídica. La bondad de este sistema de remisión consiste en su, a priori, admisibilidad constitucional. En cambio, plantea el problema de una más que segura obsolescencia de la norma jurídica ante el desarrollo técnico si no se procede a una atenta actualización de la remisión a la nueva versión de la norma técnica. Hay que señalar que el Tribunal Supremo ha admitido este tipo de remisión en su sentencia de 14 de junio de 2001 (Ar. 435/2002) ${ }^{78}$.

la existencia y relación entre dos ordenamientos a los que, sin embargo, atribuye carácter jurídico. La razón estriba en el apropiado seguimiento que este autor realiza de la doctrina del ordenamiento jurídico de Santi Romano, considerando que el ordenamiento de las entidades de normalización es de carácter jurídico y, en buena parte, derivado del ordenamiento estatal, ibidem, p. 258. En mi opinión existe, sin embargo, un auténtico ordenamiento de la técnica, dotado de sustantividad propia y cuya relación con el ordenamiento jurídico se fundamenta en interacciones recíprocas.

77 Vid. J. Esteve PARDo, Técnica, riesgo y Derecho, op. cit., pp. 173-174.

78 En la misma se realizan las consideraciones siguientes: «Los reglamentos técnicos (obligatorios), al precisar los requisitos que estimen necesario exigir a los correspondientes productos con el fin de garantizar la seguridad industrial, pueden, en vez de fijar por sí mismos las complejas especificaciones obligatorias, hacerlo por remisión a normas técnicas aprobadas por organismos de normalización, cuyo contenido -asumido en estas condiciones por el titular de la potestad reglamentaria- queda incorporado a aquéllos y participa de su fuerza obligatoria.

Esta incorporación, que los propios recurrentes califican de «fenómento habitual», si bien puede suscitar en ocasiones algún problema -como ocurre, por lo demás con todas las técnicas remisorias- no incurre en ilegalidad: se trata de una modalidad más de reglamentar, por vía de remisión, en vez de reproducir o transcribir mimética y literalmente en el propio Reglamento de seguridad el contenido correspondiente de las prolijas normas técnicas». 
Existe, sin embargo, una importante objeción a este tipo de remisión consistente en la ausencia de publicación oficial del contenido de la norma técnica. Efectivamente, el tipo de remisión que tratamos supone que la norma jurídica publicada en el correspondiente boletín oficial se limita a publicitar la referencia de la norma técnica, es decir, no reproduce o publica su contenido.

El requisito de publicidad de las normas está garantizado constitucionalmente en el artículo $9.3 \mathrm{CE}$ y es requisito para su eficacia jurídica (arts. 1.5 y 2.1 Cc.; art. 52.1 LRJPAC; y art. 24.4 de la Ley 50/1997, del Gobierno). La publicidad, según ha señalado SAINZ MORENO, presupone la publicación de la norma pero, además, implica su efectiva divulgación por cualquier medio adecuado para ello $^{79}$. En este sentido, la publicación no íntegra del contenido de la norma técnica ha sido denunciada por diferentes autores como una infracción del citado precepto constitucional ${ }^{80}$, concluyendo que no pueden imponerse de manera general normas que no han sido publicadas ${ }^{81}$. La contundencia de esta afirmación obliga a tomar en consideración una serie de elementos.

En primer lugar, cabe advertir de que, a diferencia de las normas jurídicas ${ }^{82}$, las normas técnicas elaboradas por los organismos privados de normalización estarían protegidas por los derechos de propiedad in-

79 Vid. Fernando SAINZ MORENO, «La publicidad de las normas», en La protección jurídica del ciudadano (Procedimiento administrativo y garantía jurisdiccional. Estudios en homenaje al Profesor J. González Pérez), vol. I, Madrid, Civitas, 1993, p. 122. En distintos términos, BAÑO LEÓN considera que: «(P)ublicidad de las normas no significa otra cosa que hacerlas públicas, es decir, que no sean secretas o desconocidas. Lo importante, pues, no es la publicación en el BOE o Boletín de la Comunidad Autónoma, sino buscar mecanismos que aseguren la publicidad idónea según quiénes sean los destinatarios de la norma», en «La potestad normativa de las Universidades», AA.VV., Tercer Curso sobre Régimen Jurídico de las Universidades Públicas, Madrid, Universidad Politécnica de Madrid, 1995, pp. 51-52. La argumentación de este autor nos parece muy adecuada en lo que atañe a la publicidad de las normas técnicas, ya que en el caso de las normas UNE existe esa publicidad idónea que permite su pleno conocimiento por los destinatarios de la norma.

80 Álvarez GarCía lo apunta en su trabajo «Introducción a los problemas jurídicos de la normalización industrial: normalización industrial y sistema de fuentes», $R A P, \mathrm{n}^{\circ} 147$, 1998, pp. 332-336. Advierte está autor de cómo «(E)l hecho de que las normas técnicas a las que se remiten las reglamentaciones no sean publicadas oficialmente, sino tan sólo de manera privada, no ha parecido, sin embargo, obstar para que su contenido técnico sea convertido en obligatorio por las reglamentaciones, al menos en la práctica habitual» (p. 335). Véase también J. A. CARRILlo DONAIRE, El Derecho de la seguridad..., op. cit., pp. 397-402, y A. IZQUIERDO CARRASCO, La seguridad..., op. cit., pp. 244-245.

81 Vid. V. Álvarez García, ibidem, p. 336.

82 La Ley 22/1987, de Propiedad Intelectual, dispone en su artículo 13 que «no son objeto de propiedad intelectual las disposiciones legales o reglamentarias o sus correspondientes preceptos, las resoluciones de los órganos jurisdiccionales y los actos, acuerdos, deliberaciones y dictámenes de los organismos públicos, así como las traducciones oficiales de todos los textos anteriores». Los antecedentes en este tema pueden verse en F. SAINZ MORENO, «La publicación de las normas», cit., pp. 123-124. 
telectual $^{83}$, circunstancia que ciertamente limita la divulgación indiscriminada de esas normas y, cabe reconocerlo, puede dificultar su conocimiento general. Ante la ausencia en España - hasta donde conocemos- de una declaración legal o judicial explícita en este tema, cabe destacar, por ejemplo, que la propia Comisión Europea ha reconocido derechos de autor a los organismos europeos de normalización, titulares de las normas «NN ${ }^{84}$. En segundo lugar, el hecho de que las normas técnicas ganen eficacia jurídica en los casos de remisión parece que debería obligar a su publicación íntegra en el correspondiente boletín oficial y, por tanto, el derecho de propiedad intelectual debería aquí ceder ${ }^{85}$. En mi opinión, sin

83 En este tema véase A. ARPÓN DE MENDÍvIL y R. GARCía VICENTE, «Legal Aspects of Standardisation in Spain», en Legal aspects of standardisation in the Member States of the EC and EFTA, vol. II (J. Falke y H. Schepel, ed.), Comunidad Europea, Luxemburgo, 2000, pp. 773 y ss. Sobre los casos de Francia y Alemania véase esta misma obra (J. CHAMPIGNEULLE, «Les aspects juridiques de la normalisation en droit français», vol. II, pp. 285-305, y J. FALKE, Rechtliche Aspekte der Normung in den EG-Mitgliedstaaten und der EFTA. Deutschland, vol. III, pp. 373-390. Especialmente interesante resulta el caso de este último país en el que el alcance y relevancia de las normas técnicas ha sido objeto de trato judicial. Así, resulta de interés la sentencia del Bundesgerichtshof (BGH), de 26 de abril de 1990 (Neue Juristische Wochenschrift-Rechtsprechungs-Report Zivilrecht 1990, pp. 1452-1454), en la que se trata la protección de derechos de autor de las normas DIN a partir de una remisión hecha por disposiciones administrativas de los Länder a una norma DIN en concreto (norma DIN sobre inspección de obras). El BGH reconoce que las normas DIN no se incluyen en ninguno de los tipos de normas jurídicas contenidas en el $\S 5.1$ de la ley que regula los derechos de autor (Urheberrechtsgesetz, de 9 de septiembre de 1965, modificada por Ley de 16 de junio de 1998) -precepto similar al art. 13 de la ley española de propiedad intelectual-, sin embargo, considera que una remisión puede conducir a su inclusión en ese precepto. Añade el Tribunal Supremo alemán que las normas DIN al ser tomadas como concreción de las reglas reconocidas de la técnica (allgemein anerkannten Regeln der Technik) en el arte de la construcción (Baukunst) adquieren un significado similar al de reglas de Derecho (rechtssatzähnliche Bedeutung), hecho que permitiría su publicación oficial. Las consecuencias de esta sentencia, apuntadas por FALKE (pp. 386-387), comportan la pérdida para las normas DIN de la protección derivada de los derechos de autor, lo cual no deja de ser una clara limitación al derecho de propiedad reconocido en el artículo 14 de la Ley Fundamental. Además, la reproducción íntegra de la norma DIN en una publicación oficial, y su posible copia, supone también una pérdida económica para el instituto alemán de normalización al afectar uno de los pilares de su financiación (la venta de normas supone el $60 \%$ de sus ingresos). Cabe señalar que esta sentencia del BGH fue objeto de recurso de amparo ante el Tribunal Constitucional (Bundesverfassungsgericht) por violación del referido derecho de propiedad; sin embargo, el recurso no fue admitido (acuerdo de 29 de julio de 1998). Finalmente hay que destacar que en el año 1997 los 16 Länder firmaron un convenio con el DIN en el que se especificaban los derechos de edición de determinadas normas DIN relativas a especificaciones técnicas de la construcción.

${ }^{84}$ Respuesta al Parlamento europeo del comisario M. Bangemman publicada en el $D O$ $\mathrm{n}^{\circ} \mathrm{C} 2$, de 6 de enero de 1992, p. 10.

85 En este sentido se manifiesta CARRILlo DONAIRE al considerar «que los derechos morales y económicos derivados de la propiedad intelectual decaen automáticamente cuando una norma técnica es declarada obligatoria por la remisión que a ella hace un Reglamento de Seguridad. Esta solución se apoya en la dicción del art. 13 (...) de la Ley de Propiedad Intelectual (...), por lo que cabe entender que el reenvío normativo a una norma tal supone su exclusión del objeto legal de la propiedad intelectual; lo que sumado a la obligación que recae sobre las entidades de normalización en orden a facilitar a las Administraciones requirentes las normas técnicas cuyas referencias se incluyan en los reglamentos por ellas elaborados (...), 
embargo, existen argumentos que permiten considerar aceptable la mera referencia a una norma técnica por parte de una norma jurídica sin que aquélla deba ser objeto de reproducción íntegra en la publicación oficial.

Advirtamos que esta cuestión es objeto de tratamiento en todos los Estados europeos en que existen organismos privados de normalización. En todos ellos la regla general en los casos de remisión a normas técnicas es la no publicación oficial de su contenido. También, y al igual que en el caso español, esta realidad es puesta en cuestión, exigiéndose la publicidad oficial de la norma con la finalidad de garantizar su conocimiento general. Así, por ejemplo, en el caso alemán OSSENBÜHL ${ }^{86}$ exigía hace ya tres décadas la publicación de la norma técnica en los boletines oficiales con la única excepción de una imposibilidad técnica (p. ej., planos). La realidad legislativa es, sin embargo, la que es y cuenta, además, con un temprano pronunciamiento judicial del año 1961 proveniente del Bundesverwaltungsgerichts (Sala de lo contencioso del Tribunal Supremo ${ }^{87}$, en el que se establecen los requisitos mínimos para admitir la remisión normativa a normas técnicas ya publicadas: 1) se debe asegurar la identidad del texto objeto de publicación; 2) cualquiera debe tener a su libre disposición el conocimiento del objeto de la remisión; y 3) el acceso debe ser suficientemente fácil. Por tanto, no se excluye la única publicación de la norma por los organismos de normalización y su acceso mediante compra, si bien en este caso la doctrina considera que su precio no debe ser excesivamente caro $^{88}$.

Existen, además, suficientes argumentos que justifican la no publicación de las normas técnicas en los boletines oficiales. Entre otros FALKE señala, por ejemplo, el excesivo esfuerzo que supondría la pu-

haría posible la directa publicación de la norma técnica en cuestión en el Boletín Oficial correspondiente (por ejemplo, como anexo técnico de la disposición reglamentaria remitente)», en El Derecho de la seguridad..., op. cit., pp. 401-402. Pese al impecable planteamiento de este autor, el intento de suplir una carencia -la no publicación oficial de la norma técnica-con la vulneración de un derecho no nos parece plenamente justificada. Como exponemos en este apartado existen razones para entender que el régimen actual de publicidad de las normas técnicas es el adecuado y que la publicación oficial supondría más inconvenientes que ventajas. Además, la obligación contenida en el art. 10, letra o, del RICSI referida por el citado autor no puede entenderse de ningún modo como una cesión a la Administración de los derechos de propiedad intelectual de los que es titular el organismo de normalización. La finalidad de ese precepto consiste en que aquellas normas referidas desde reglamentos obren en depósito de la Administración para su consulta pero no para su publicación.

86 F. OssEnBÜHL, «Die verfassungsrechtliche Zulässigkeit der Verweisung als Mittel der Gesetzgebungstechnik», DVBl, 1967, pp. 405-407.

87 Sentencia de 29 de agosto de 1961, publicada en Neue Juristische Wochenschrift, 1962, p. 506. Véase E. DENNINGER, Verfassungsrechtliche Anforderungen an die Normsetzung im Umwelt und Technikrecht, Nomos, Baden-Baden, 1990, pp. 163-165; J. FALKE, Rechtliche Aspekte der Normung..., op. cit., pp. 253-256.

88 Vid. E. DENNINGER, ibid., p. 164; J. FALKe, ibid., p. 254. 
DA-2003, núms. 265-266. MARC TARRÉS VIVES. Las normas técnicas en el Derecho Administrativ...

blicación oficial de las normas técnicas objeto de remisión ${ }^{89}$. También cabe destacar la importante fuente de financiación que supone para los organismos de normalización la venta de normas. En este sentido, una pretendida publicación íntegra de las normas técnicas en publicaciones oficiales debería suponer una compensación para los organismos de normalización que, por otro lado, podría poner en cuestión su independencia frente al Estado. Pero, además, ello obligaría a negociar también con organizaciones internacionales o regionales, pues en muchos casos las normas técnicas nacionales se limitan a traducir el contenido de otras elaboradas por aquéllas, con lo que existe una cotitularidad sobre la norma. Habría también razones de «seguridad técnica» ya que los organismos de normalización están obligados a mantener el contenido de la normas según el estado de desarrollo científico y técnico ${ }^{90}$, debiendo publicar inmediatamente el resultado de su trabajo. Esa inmediatez en la publicación de la última versión de la norma técnica no estaría asegurada en el otro caso. En relación a este punto hay que destacar una importante diferencia en el modo de publicar las posteriores modificaciones de un texto. En el caso de los boletines oficiales se procede, por regla general, a dar a conocer el nuevo texto manteniendo en vigor el antiguo en lo no alterado -ello obliga a manejar textos alternativos, cosa a la que los juristas ciertamente estamos acostumbrados pero que no resulta excesivamente operativo-; en cambio, en el caso de los organismos de normalización, éstos siempre proceden a una nueva publicación íntegra de la norma, lo cual evita posibles disfunciones. En último lugar, hay que reconocer que los destinatarios de normas técnicas no son, en la mayoría de supuestos, el común de los ciudadanos, sino un grupo de personas relativamente reducido e incluso determinable que, de modo directo o indirecto, puede haber tenido alguna participación en la elaboración o valoración de la norma ${ }^{91}$.

En lo que respecta al caso español, el régimen de publicidad de las normas UNE elaboradas por AENOR se halla contenido en el RD

${ }^{89}$ Este autor destaca cómo sólo el organismo de normalización electrotécnica (Deutsche Elektrotechnische Kommission) utilizó en el año 1998 un total de 32.369 páginas para publicar un total de 1.056 normas, ibid., p. 255.

90 En el caso de las normas DIN, la norma DIN 820 (edición febrero 1974), Parte 4, apartado 4, establece su examen como mínimo cada cinco años. Puede consultarse en Grundlagen der Normungsarbeit des DIN, Beuth, Berlín, 1995, p. 335.

91 De hecho, como reconoce E. GARCía LLOVET, la complejidad que ofrece el ordenamiento a partir de la propia estructura técnica de las normas revela que sus destinatarios son los «iniciados» que «disponen de los conocimientos técnicos suficientes para adecuar sus conductas a las prescripciones que se establecen en la norma». «Iniciados» que, además, «circulan con una extraordinaria fluidez entre el sector público y el sector privado bajo muy diferentes fórmulas», en «Conocimiento de la norma y seguridad jurídica», Derecho Administrativo en el umbral del siglo XXI (Homenaje al Profesor Dr. D. Ramón Martín Mateo), t. II, Tirant lo Blanch, Valencia, 2000, pp. 1734-1735. 
2200/1995 (RICSI). Como organismo de normalización reconocido, AENOR asume un conjunto de obligaciones hacia la Administración que, en lo referente a las normas técnicas aprobadas, se traduce en la necesaria remisión mensual de la relación de normas aprobadas y anuladas en ese período, identificándolas por su código alfanumérico y título para su publicación indicativa en el BOE (art. 11.f RICSI). El objeto de esta publicación es el de reconocer esas normas técnicas como «normas españolas», esto es, como normas UNE, y con independencia de que puedan ser o no objeto de posterior remisión desde normas reglamentarias. El RICSI establece un auténtico mandato sobre AENOR al encomendarle las funciones de edición, impresión y venta de las normas, cuyos precios -señala el art. 11.i- se fijarán en el marco del convenio anual de colaboración de este organismo con la Administración. Otras obligaciones destinadas a asegurar el conocimiento y acceso público a las normas UNE son: mantener un registro permanente actualizado de normas españolas en tramitación y editadas, así como durante el período necesario las anuladas que afecten a la legislación nacional (art. 11.g); editar y publicar, al menos una vez al año, un catálogo de normas españolas actualizado (art. 11. j); disponer de un fondo documental de textos actualizados de las normas españolas, a disposición del público, para su consulta gratuita, así como atender las peticiones de información que se le realicen sobre las normas o proyectos de normas (art. 11. $k$ ); disponer de un medio propio de difusión, editado con periodicidad mínima trimestral, que informe sobre las novedades en materia de normalización de organismos nacionales e internacionales (art. 11. $l$ ); y facilitar, a requerimiento de las Administraciones públicas, las normas cuyas referencias se incluyan en los reglamentos por ellas elaborados (art. 11.o).

\section{a.2) El reenvío dinámico o remisión a la norma técnica}

En este tipo de remisión la norma jurídica remitente no precisa una norma técnica en un momento concreto, sino que señala la norma en su versión válida presente o futura. Es, por ejemplo, el caso de las remisiones genéricas a la norma UNE 66500 (EN 45000 ) que se contienen en el RICSI con relación a la acreditación de las entidades que integran la infraestructura para la calidad y la seguridad industrial ${ }^{92}$. La remi-

92 En este caso se refleja sólo el número de la norma pero sin indicar su fecha ni, por lo tanto, su versión, por lo que debe entenderse que ésta será la que esté vigente en cada momento». Una remisión del mismo estilo se contiene, por ejemplo, en el art. 17 del RD 2085/1994, de 20 de octubre, que aprueba el Reglamento de instalaciones petrolíferas, en donde se dispone que los sistemas de seguridad a los que se refiere ese precepto «serán diseñados de conformidad a las normas UNE 23501 a 23507, ambas inclusive». 
DA-2003, núms. 265-266. MARC TARRÉS VIVES. Las normas técnicas en el Derecho Administrativ...

sión dinámica o flexible ofrece como indudable ventaja el superar las rigideces del sistema de remisión estática al quedar abierta la posibilidad de aceptar la modificación de las normas técnicas remitidas, sin necesidad de proceder a la actualización de la norma legal remitente. Sin embargo, este modelo plantea serias reservas a su validez jurídica ya que, como advierte ESTEVE PARDO, el ordenamiento pierde el dominio sobre la norma que a él se incorpora ${ }^{93}$. De forma gráfica la norma remitente pasa a convertirse en una «ley en blanco», en una «ley de contenido movible».

Lo cierto es que este tipo de remisión ha sido, con razón, objeto de importantes objeciones desde la doctrina administrativista española ${ }^{94}$. El motivo radica en que la adaptación automática de la norma reglamentaria remitente a la norma técnica remitida convierte en la práctica al organismo privado de normalización en titular de un poder cuasi reglamentario autónomo («cuasi» porque como ya sabemos no se trata de reglas de Derecho). Es decir, mediante la remisión dinámica el legislador realiza una delegación fáctica de su competencia normativa en un organismo privado al permitirle alterar el contenido normativo de un precepto legal. No nos encontramos, pues, ante una creación ex novo de derecho por sujetos privados, sino ante una sustitución de la potestad reglamentaria o, en su caso, legislativa, lo cual atenta contra los principios del Estado de Derecho y, en consecuencia, no es admisible constitucionalmente.

En este modelo de remisión es interesante hacer notar la distinción que en la doctrina alemana ${ }^{95}$ se realiza entre «normergänzende gleitende Verweisung» (remisión dinámica a una norma agregante) y «normkonkretisierende gleitende Verweisung» (remisión dinámica a una norma concretizadora). En la primera variante, la norma jurídica aparece como incompleta y toma con efectos obligatorios el contenido de una

93 Vid. J. Esteve Pardo, Técnica, riesgo y Derecho, op. cit., p. 174.

94 Principalmente J. Esteve PARdo, ibid.; V. Álvarez García, La normalización...., op. cit., pp. 159-181. En cambio, para IZQUIERDO CARRASCO esas objeciones deben matizarse a la luz del art. 11, letra h), del RICSI (en el que se obliga a los organismos de normalización a dar cuenta al órgano competente de la Administración pública que lo reconoció del inicio y la finalización de los procesos de revisión o anulación de normas españolas que tengan incidencia sobre reglamentaciones de seguridad industrial). Esta previsión muestra, según este autor, «que no existe tal pérdida absoluta de dominio y conocimiento del ordenamiento jurídico general sobre el contenido de la norma técnica, pues no sólo se comunica a la Administración el inicio de los trabajos de revisión o anulación, lo que permite a la Administración decidir una intervención activa en tales trabajos; sino que también se le comunica el resultado final, con lo que la Administración puede decidir el mantener o no la remisión, según dicho resultado satisfaga o no las exigencias de seguridad que considere esenciales», en La seguridad de los productos industriales, op. cit., pp. 257-258.

95 Véase P. MARBURger, Die Regeln der Technik im Recht, op. cit., pp. 390-407; E. DENNINGER, Verfassungsrechtliche Anforderungen an die Normsetzung..., op. cit., pp. 139-147; J. FALKE, Rechtliche Aspekte der Normung..., vol. III, op., cit., pp. 250-253; P. MARBURGER/M. KLEIN, «Bezugnahme auf technische Normen im deutschen Uniwelt-und Technikrecht», en Jahrbuch des Unwelt-und Technikrechts 2001, Berlín, 2001, pp. 166-169. 
norma técnica prescindiendo de cuál sea su versión (p. ej., sería el caso en que una norma reglamentaria remitiera de manera genérica su contenido técnico a las especificaciones técnicas elaboradas por un organismo de normalización nacional o de ámbito internacional ${ }^{96}$. Esta modalidad de remisión sería unánimemente considerada como inconstitucional ${ }^{97}$. Sin embargo, no cabe duda de que por razones de flexibilidad las regulaciones sobre nuevas tecnologías son realmente un ámbito propicio a este tipo de remisiones. La segunda modalidad de remisión, por el contrario, es plenamente aceptada ya que en ella la norma jurídica remitente establece unos requisitos generales no detallados que encuentran su concreción en normas técnicas a través de cláusulas generales o conceptos jurídicos indeterminados. A este tipo de remisión se le presta especial atención en el siguiente apartado.

\section{B) La remisión indirecta al ordenamiento de la técnica: cláusulas generales y norma técnica}

La búsqueda de especificaciones técnicas extramuros del ordenamiento jurídico encuentra en la llamada remisión indirecta o innominada el instrumento actualmente más usado por el legislador. En este caso el objeto de remisión no se expresa mediante la norma técnica, sino a través de la llamada cláusula técnica por la que se señala de manera genérica el estado de la técnica y de los conocimientos científicos ${ }^{98}$. Las normas técnicas, en este caso, son un elemento de referencia importante pero no determinante. Como bien advierte ESTEVE PARDO, " $(L)$ a cláusula técnica no se materializa en una remisión normativa, sino que apunta a un concepto jurídico indeterminado como es el que se expresa con los términos «estado de la técnica», «mejor tecnología disponible», «mejores técnicas conocidas» u otros semejantes. Para su concreción, las normas técnicas, de haberlas, pueden ser un elemento indiciario de gran valor, pero no han de ser la referencia determi-

96 Pese a su inadmisibilidad, lo cierto es que este tipo de remisión existe tanto en Alemania como en España. Así, por ejemplo, la Resolución -acto normativo que debería contener en última instancia las especificaciones técnicas a aplicar o realizar una concreta remisión- de 28 de diciembre de 2000 (BOE , de 30.12.2000), de la Secretaría de Estado de Telecomunicaciones y para la Sociedad de la Información. La misma tiene por objeto modificar la primera oferta de acceso al bucle de abonado de Telefónica de España -una cuestión de interés para los usuarios-, estableciendo en el anexo III del apartado 5 (Aspectos de facturación) del Anexo II (Modificaciones requeridas) que: «Deben ser incluidas en el catálogo de señales las especificaciones técnicas aprobadas por el ETSI sobre SDLS».

97 Concretamente, en Alemania, se alega la infracción contra el principio democrático de la Constitución (art. 20.2 GG) y la imposibilidad de pensar en una delegación legislativa en el marco del art. 80 GG.

98 Vid. J. ESTEVE PARDO, «La adaptación de las licencias a la mejor tecnología disponible», $R A P, \mathrm{n}^{\circ} 149$, p. 46. 
nante» ${ }^{99}$. Se trata, pues, en este caso de una recepción de conocimientos no jurídicos -contemplados en normas o reglas técnicas-destinados a lograr la concreción de conceptos jurídicos indeterminados ${ }^{100}$. Lo importante en este caso es que el contenido de la norma jurídica resulta fijado -aparentemente y en última instancia- por la Administración concedente de la licencia o por el juez encargado de su control ${ }^{101}$.

Mediante la cláusula técnica se realiza una remisión permanente a un determinado grado de desarrollo tecnológico existente en un momento concreto y, en ocasiones, a su disponibilidad efectiva, tanto en términos técnicos como económicos ${ }^{102}$. Efectivamente, el uso de las expresiones «reglas generalmente (re)conocidas» ${ }^{103}$, «estado (progreso, evolución) de la técnica» ${ }^{104}$, o «estado de la ciencia y de la

\section{Ibidem, p. 47.}

100 Esta cuestión es analizada atinadamente por este mismo autor en su obra Autorregulación. Génesis y efectos, op. cit., especialmente en las pp. 89-93, bajo el ilustrativo título de «La remisión a la mejor tecnología disponible como fórmula de relación entre sistemas, el del Derecho y el de la técnica. De los conceptos jurídicos indeterminados a los conceptos no jurídicos».

101 Como señala EsTEVE PARDo en estos casos, «(L)a función de la norma técnica será entonces la de constituir un elemento de concreción del ordenamiento allí donde éste recurre a los conceptos jurídicos indeterminados que se expresan en la cláusula técnica. La normas técnicas aportan así los criterios cualificados de los expertos técnicos y éste es su principal activo. Es el informe general de los expertos y peritos. De ahí que pueda considerarse acertada la expresión que se acuña por la jurisprudencia alemana para valorar las normas técnicas como un dictamen anticipado de peritos (antizipierte Sachverständige Gutachten). Lo que el juez encuentra en las normas técnicas no es, pues, una norma que le vincule y tenga necesariamente que aplicar, sino un dictamen de técnicos, posiblemente con un amplio reconocimiento en los ámbitos especializados pero que, en función de las circunstancias y su apreciación por el propio juez, puede éste no considerar el dictamen que la norma técnica encierra», Técnica, riesgo y Derecho, op. cit., pp. 176-177. El mismo autor estudia con más detalle este tema en su monografía Autorregulación. Génesis y efectos, op. cit.

102 Es el caso de la Directiva 96/61/CE, de 24 de septiembre de 1996, relativa a la prevención y al control integrados de la contaminación ( $D O \mathrm{n}^{\circ} \mathrm{L} 257$, de 10 de octubre de 1996), cuyo artículo 11 establece que: «Los Estados miembros velarán porque las autoridades competentes estén al corriente o sean informadas acerca de la evolución de las mejores técnicas disponibles». La definición de «mejores técnicas disponibles» se encuentra en el apartado 11 del artículo 2 de la citada Directiva, donde puede leerse que por «disponibles» se entenderá: «las técnicas desarrolladas a una escala que permita su aplicación en el contexto del sector industrial correspondiente, en condiciones económica y técnicamente viables, tomando en consideración los costes y los beneficios, tanto si las técnicas se utilizan o producen en el Estado miembro correspondiente como si no, siempre que el titular pueda tener acceso a ellas en condiciones razonables». Con idéntica redacción puede verse el art. 3, letra ñ) de la Ley 16/2002, de prevención y control integrados de la contaminación.

103 Así, por ejemplo, el artículo 4.c) de la Ley catalana 13/1987, de seguridad industrial, o, de modo más explícito, el artículo 6.2.a) de la también catalana Ley 3/1998, de intervención integral de la Administración ambiental, en donde se refiere que las instalaciones objeto allí de regulación deberán ajustarse, en caso de ausencia de reglamentación o instrucciones específicas, «a las normas técnicas de reconocimiento general».

104 Es el caso del artículo 3.2 de la Ley 38/1972, de protección del ambiente atmosférico; también de la Ley 31/1995, de 8 de noviembre, de prevención de riesgos laborales, cuyo artículo 6.2 establece: «Las normas reglamentarias indicadas en el apartado anterior se ajusta- 
técnica» ${ }^{105}$, refleja estados distintos, cada vez más perfeccionados, del conocimiento técnico ${ }^{106}$. La gradación establecida por estas cláusulas generales conforma un triple nivel de seguridad técnica (Dreistufenschema) que, por ejemplo, fue recogido en una importante decisión del Tribunal Constitucional alemán (Kalkar-Beschluss) ${ }^{107}$, de ocho de agosto de 1978, en la que se reconocía que a través de ellas las autoridades administrativas y los jueces deben equilibrar el déficit de regulación que puede ofrecer la normativa a aplicar.

El uso de este tipo de expresiones por parte de las normas jurídicas muestra una renuncia explícita del legislador a la elaboración detallada de reglamentaciones técnicas que, en verdad, podrían convertirse en obsoletas al poco tiempo de su publicación. Cabe reconocer, sin embargo, que el uso de conceptos jurídicos indeterminados constituye una técnica legislativa ampliamente utilizada en muy diferentes ámbitos (productos industriales, tecnologías de la información, medio ambiente, economía) ${ }^{108}$. Aunque, bien es cierto, existe en el uso de aquellos

en todo caso, a los principios de política preventiva establecidos en esta Ley, mantendrán la debida coordinación con la normativa sanitaria y de seguridad industrial y serán objeto de evaluación y, en su caso, de revisión periódica, de acuerdo con la experiencia en su aplicación y el progreso de la técnica»-cursiva nuestra-.

${ }^{105}$ Por ejemplo, el artículo 5.1 de la Ley catalana 6/1993, de residuos, en el que puede leerse: «Mediante disposición reglamentaria se regulará la gestión de determinadas categorías de residuos cuya naturaleza, características o especial problemática y cuya necesaria adaptación al progreso científico y técnico lo exijan»-cursiva nuestra-.

106 Las normas generalmente reconocidas aluden a aquellos procedimientos que, una vez comprobados en la praxis y según la opinión mayoritaria de los expertos, se corresponde con el desarrollo técnico del momento. El estado de la técnica agrupa procedimientos, instalaciones y modos de producción avanzados, cuya idoneidad práctica está asegurada. El estado de la ciencia y de la técnica se refiere a los últimos conocimientos científicos que todavía no son de aplicación general. En este sentido, véase J. SOLÉ I FeLíu, El concepto de defecto del producto en la responsabilidad civil del fabricante, Tirant lo Blanch, Valencia, 1997, pp. 407412 y 536-539. Recogiendo la doctrina alemana, refiere que las «reglas de la técnica» son generalmente reconocidas «cuando siendo conocidas por los especialistas que actúan en el sector afectado, se consideran correctas por la mayoría de ellos y resultan acreditadas en la práctica»; el «estado de la técnica» refiere una aptitud práctica que, en cambio, no goza de general reconocimiento; el «estado de la ciencia y de la técnica» sería el nivel que más se aproxima al «verdadero frente del progreso técnico». Añade, finalmente este autor, la distinción entre «estado de la ciencia» y «estado de la ciencia y de la técnica», el primero aludiría «al conjunto de conocimientos teóricos, incluyendo también los pertenecientes a sectores no técnicos, con independencia de si tales conocimientos han sido o no aplicados en la práctica, o de si todavía no han entrado a formar parte de la técnica»; el segundo -en relación al «estado de la técnica»- sobrepasa el estricto marco específico de la técnica, para abarcar todos los conocimientos científicos existentes en cualquier otra disciplina científica, además de la técnica: química, biología, medicina, etc. En este sentido, también forma parte del estado de la ciencia y de la técnica cualquier conocimiento técnico que aún no es técnicamente viable».

107 Sentencia publicada en BverfGE 49, 80 (especialmente p. 135 y ss.). Véase J. FALKE, Rechtliche Aspekte..., op. cit., p. 259 y ss.

108 Vid. C. D. CiRIANO VELA, Administración económica y discrecionalidad (Un análisis normativo y jurisprudencial), Lex Nova, Valladolid, 2000, p. 132 y ss. 
DA-2003, núms. 265-266. MARC TARRÉS VIVES. Las normas técnicas en el Derecho Administrativ...

conceptos un componente valorativo o discrecional mayor o menor según los casos. Así, en lo relativo a las disciplinas científico-técnicas se argumenta que el margen de discrecionalidad es menor en atención a su comprobación fáctica. La realidad, sin embargo, permite observar que el pretendido carácter unívoco de esas disciplinas sería cuestionable dadas las muestras de autorrefutación que desde ellas mismas se ofrece ${ }^{109}$. Por este motivo, formulaciones del tipo «estado de la técnica» son denunciadas por BECK como el equivalente a «leyes implícitas de plenos poderes» ${ }^{10}$. Ahora bien, contra lo que pudiera pensarse, esta situación no comporta una Dictadura de la técnica, circunstancia que el propio experto aborrecería en su significado político, pero, sin duda, coloca a la tecnocracia en una posición ciertamente privilegiada en la conformación del discurso político de todas aquellas cuestiones relacionadas con la seguridad de las personas o, entre otras muchas, la preservación del medio ambiente.

En el fondo, la cuestión que subyace en cada una de las opciones descritas es la relación entre la norma jurídica y la norma técnica y, más en concreto, el modo - directo o indirecto-que hace posible que el ordenamiento jurídico atribuya relevancia a ese último tipo de norma. La dicotomía entre norma jurídica y norma técnica aparece, pues, clara. La norma técnica, en palabras de CHARBONNEAU, sería "parcelaria» y limitada a unos efectos científicamente contrastados ${ }^{111}$. Contrariamente a la norma jurídica, la norma técnica no puede pretender hacer frente a aquellas situaciones de hecho más corrientes en las que, de manera simultánea, intervienen demasiados parámetros. Cabe, sin embargo, reconocer que la proliferación de normas o reglas técnicas y su mutación constante pueden provocar una deslegitimación de las propias normas jurídicas en atención a su obsolescencia. De este modo, pese a su inverificabilidad para el común de los mortales, la norma técnica se impone como el discurso hermenéutico de la tecnocracia que cambia en función de la coyuntura económica y de los progresos de la investigación científica.

En cuanto método de remisión, el de las cláusulas generales puede ser considerado como la auténtica puerta de entrada del ordenamiento social de la técnica. De modo expresivo SCHMIDT-PREUSS ha definido

109 En este sentido, vid. U. BECK, Políticas ecológicas en la edad del riesgo, op. cit., p. 125 y ss. El sociólogo alemán considera que esa autorrefutación pública no indica fallo de la ciencia «sino un nuevo estado de su desarrollo» (p. 203).

110 Así, añade este autor, «(E)l gobierno, el parlamento y la jurisprudencia se privan a sí mismos del poder y se convierten, en la medida en que las consecuencias de la técnica, más que todos los proyectos de ley, alteran la sociedad y determinan el orden del día de la política, en sucursales, órganos ejecutores, meros ayudantes para la legitimación de los peritos y las asociaciones de ingenieros, verdaderos gobernantes provistos con el cetro del conocimiento en la materia y el manto de la necesidad técnica»-cursiva entrecomillada en el texto-,ibidem, pp. 210-211.

111 S. Charbonneau, «Norme juridique et norme technique», en Archives de Philosophie du Droit, 1983, nº 28. 
esta práctica legislativa como el puente hacia una normatividad autorregulativa en el marco de una legislación abierta («Königsweg einer für selbstregulative Normen offenen Gesetzgebung») ${ }^{112}$, cuya máxima expresión se halla en las normas elaboradas por los organismos privados de normalización. La existencia de estas normas en el seno de la sociedad responde a las limitaciones del Derecho como instrumento regulador de la técnica. Efectivamente, el carácter predectivo del Derecho y la voluntad estática por no decir inmanente de la norma jurídica casa mal con el dinamismo ofrecido desde la técnica. Por este motivo la remisión estática o nominada aunque ofrece seguridad jurídica resulta inadecuada para la dirección de la técnica. Ese es precisamente el problema del Derecho: lograr dirigir el progreso técnico sin malograrlo pero sin ser sobrepasado por él. Desiderátum, este último, difícil de compaginar con la remisión dinámica que, como se ha dicho, es inaceptable jurídicamente. Por el contrario, la concreción de los conceptos jurídicos indeterminados constituye un mecanismo que permite residenciar la última decisión técnica dentro de los márgenes del Estado de Derecho al posibilitar cierta flexibilidad con relación a la determinación de lo que debe entenderse por «estado de la técnica» $\mathrm{o}$ «reglas reconocidas de la técnica».

112 M. SCHMIDT-Preuss, «Normierung und Selbstnormierung aus der Sicht des Öffentlichen Rechts», Zeitschrift für das gesamte Lebensmittelrecht, n 3, 1997, p. 254. 